\title{
VARIAÇÃO DO TEOR DE CARBOIDRATOS TOTAIS EM QUEIJOS MINAS FRESCAL E MINAS PADRÃO
}

\section{eloisa Castellucci Caruso}

Economista Doméstica

Orientador: Prof. Dr. ANTONIO JOAQUIM DE OLIVEIRA

Dissertação apresentada à Escola Superior de Agricultura "Luiz de Queiroz", Universidade de São Paulo, para obtenção do título de Mestre em Ciências, Área de Concentração: Ciência e Tecnologia de Alimentos.

PIRACICABA

Estado de São Paulo - Brasil

Outubro - 1997 
Dados Internaclonais de Catalogação na Publicação (CIP) DIVISÃo DE BIBLIOTECA E DOCUMENTAÇÃo - Campus "Luiz de Quelroz"/USP

\author{
Caruso, Eloisa Castellucel \\ Varlaçăo do teor de carboldratos totals em queljos Minas Frescal e Minas Padråo / \\ Eloisa Castellucel Caruso. - PIracicaba, 1997. \\ $54 \mathrm{p}$. \\ Dissertaçăo (mestrado) - Escola Superior de Agricultura Luiz de Queiror, 1997. \\ Bibllografia. \\ 1. Carboldratos (teor) 2. Queljo Minas Frescal 3. Quelio Minas Padr3o I. Titulo
}




\section{VARIAÇÃO DO TEOR DE CARBOIDRATOS TOTAIS EM QUEIJOS MINAS FRESCAL E MINAS PADRÃO}

\section{eloisa Castellucci Caruso}

Dissertação apresentada à Escola Superior de Agricultura "Luiz de Queiroz", Universidade de São Paulo, para obtenção do título de Mestre em Ciências, Área de Concentração: Ciência e Tecnologia de Alimentos.

PIRACICABA

Estado de São Paulo - Brasil

Outubro - 1997 


\section{VARIAÇÃO DO TEOR DE CARBOIDRATOS TOTAIS EM QUEIJOS MINAS FRESCAL E MINAS PADRÃO}

Eloisa Castellucci Caruso

Aprovada em: 17.11.1997

Comissão julgadora:

Prof. Dr. Antonio Joaquim de Oliveira

ESALQ/LCT

Prof. Dr. Claudio Rosa Gallo

ESALQ/LCT

Prof. Dr. Wilson Roberto Soares Mattos

ESALQ/LZT

Prof. Dr. Antonio JoAquim De OlveIra Orientador 
Aos meus pais

João Gustavo e Maria Inês

Aos meus irmãos

André e Raquel

\section{DEDICO}

Ao meu noivo

Luís Orlindo

OFEREÇO 


\section{AGRADECIMENTOS}

- Aos meus pais, que sempre me apoiaram e incentivaram, além de me proporcionarem condições para a realização deste trabalho;

- Ao Prof. Antônio Joaquim de Oliveira, pelo carinho, dedicação e amizadade durante a execução deste trabalho;

- À Escola Superior de Agricultura "Luiz de Queiroz", em especial ao Departamento de Ciência e Tecnologia Agroindustrial, seus professores e funcionários, pelos ensinamentos e pelo auxílio na realização deste trabalho;

- Aos amigos Cleomar Maria de Carvalho, Carlos Eduardo Garcia e Valmir Eduardo Alcarde, pelos auxilios nos momentos de maiores dificuldades no laboratório;

- A Coordenação de Aperfeiçoamento de Pessoal de Nível Superior (CAPES), pela concessão da bolsa de estudo;

- Ao prof. Dr. Roberto Simionato de Moraes e Luís Orlindo Tedeschi pela orientação nas análises estatísticas.

- A todos que direta ou indiretamente contribuiram para a realização deste trabalho. 


\section{SUMÁRIO}

\section{Página}

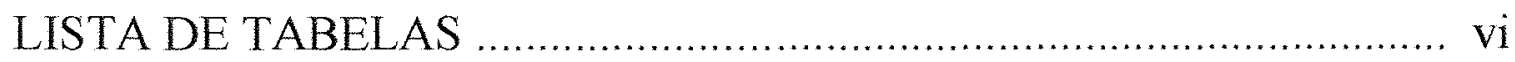

LISTA DE APÊNDICE ............................................................. ix

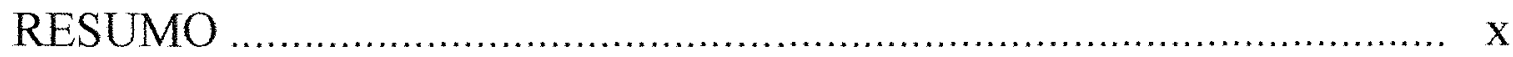

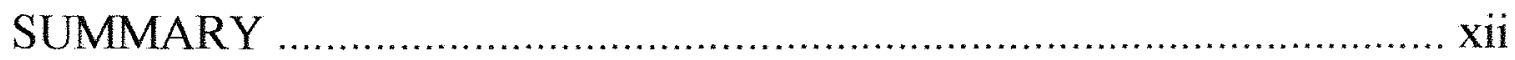

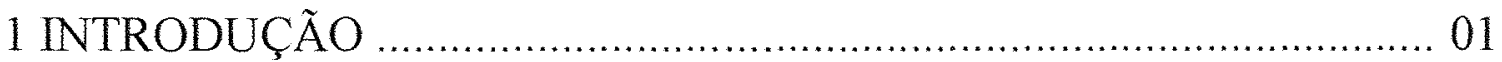

2 REVISÃO DA LITERATURA ............................................... 03

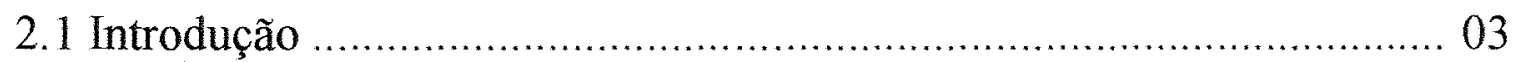

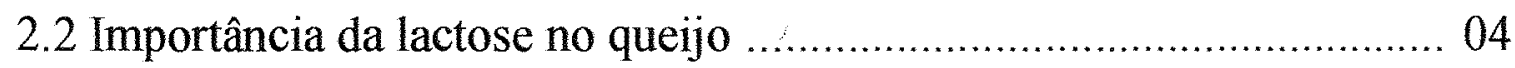

2.3 Metodologia da análise ....................................................... 05

2.4 Variação do teor de lactose .......................................................... 08

3 MATERIAL E MÉTODOS …...................................................... 13

3.1 Queijo Minas Frescal .............................................................. 13

3.2 Queijo Minas Padrão .................................................................. 13

3.3 Preparo das amostras para as análises ........................................ 14

3.4 Análises fisico-químicas ........................................................ 14

3.4.1 Frequência das análises ................................................. 14

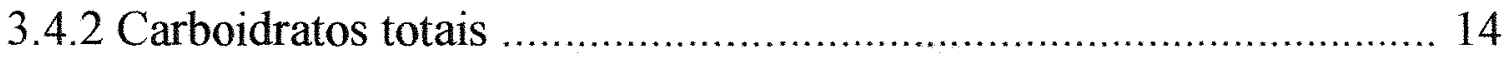

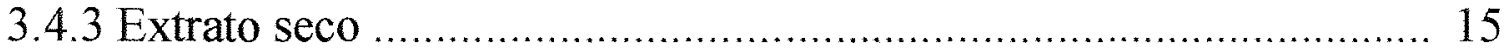

3.4.4 Acidez titulável ................................................................ 15

3.5 Análise estatística ............................................................. 16

3.6 Recuperação da lactose .............................................................. 17 
3.6.1 Com variação da quantidade de lactose adicionada .................... 17

3.6.2 Sem variação da quantidade de lactose adicionada .................... 17

3.6.3 Com adição da lactose antes da clarificação ............................. 18

4 RESULTADOS E DISCUSSÃO .......................................... 19

4.1 Recuperação da lactose .......................................................... 19

4.2 Queijo Minas Frescal ................................................................ 22

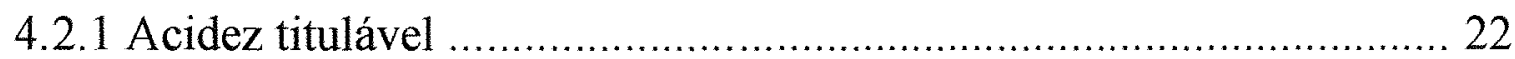

4.2.2 Carboidratos totais .......................................................... 26

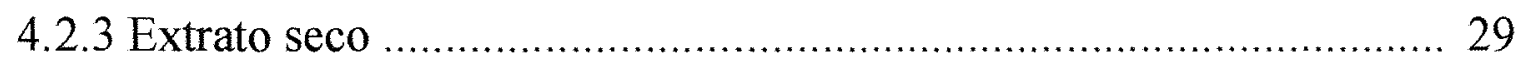

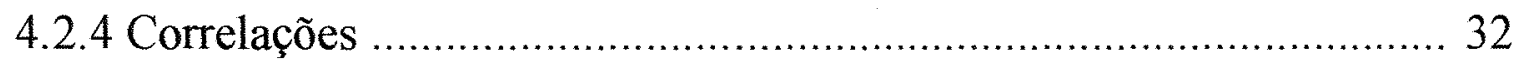

4.3 Queijo Minas Padrão .......................................................... 33

4.3.1 Acidez titulável .............................................................. 33

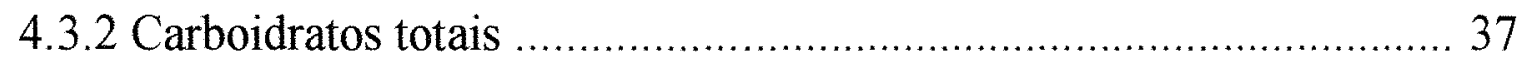

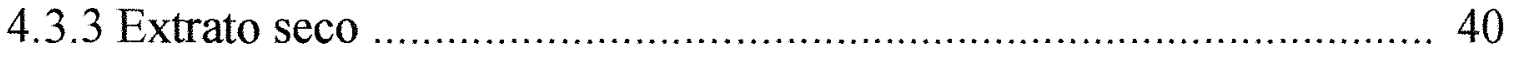

4.3.4 Correlações ................................................................... 43

5 CONCLUSÕES ................................................................... 44

REFERÊNCIAS BIBLIOGRÁFICAS …...................................... 46 


\section{LISTA DE TABELAS}

Tabela 1. Recuperação de lactose pelo método fenol-ácido sulfúrico ...... 20

Tabela 2. Recuperação de lactose pelo método fenol-ácido sulfúrico ...... 20

Tabela 3. Efeito da clarificação sobre a recuperação da lactose ............... 21

Tabela 4. Análise de variância para acidez titulável nos queijos Minas

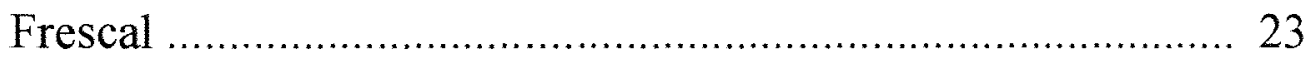

Tabela 5. Médias de acidez titulável em queijos Minas Frescal e teste de Tuckey ao nível de 5\% de probabilidade .............................. 23

Tabela 6. Desdobramento de lotes dentro de semanas, para Ac\%Q Minas Frescal

Tabela 7. Desdobramento para regressões nas semanas, para Ac\%Q Minas Frescal 25

Tabela 8. Análise de variância para carboidratos totais nos queijos Minas Frescal 26

Tabela 9. Médias de carboidratos totais \% queijos Minas Frescal e teste de Tuckey ao nível de $5 \%$ de probabilidade 27

Tabela 10. Desdobramento para regressões nas semanas, para CT\%Q Minas Frescal ............................................................. 28

Tabela 11. Análise de variância para extrato seco \% queijo Minas Frescal 29

Tabela 12. Médias de extrato seco \% queijo Minas Frescal e teste de Tuckey ao nível de $5 \%$ de probabilidade ................................ 30

Tabela 13. Desdobramento de lotes dentro de semanas, para ES\%Q Minas Frescal 31

Tabela 14. Desdobramento para regressões nas semanas, para ES\%Q 
Minas Frescal

Tabela 15. Correlações entre parâmetros estudados para o queijo Minas Frescal

Tabela 16. Análise de variância para acidez titulável nos queijos Minas

Padrão 34

Tabela 17. Médias de acidez titulável em queijos Minas Padrão e teste de Tuckey ao nível de $5 \%$ de probabilidade 35

Tabela 18. Desdobramento de lotes dentro de semanas, para Ac\%Q Minas Padrão 36

Tabela 19. Desdobramento para regressões nas semanas, para $\mathrm{Ac} \% \mathrm{Q}$ Minas Padrão 37

Tabela 20. Análise de variância para carboidratos totais \% queijo Minas Padrão 38

Tabela 21. Médias de carboidratos totais \% queijos Minas Padrão e teste de Tuckey ao nível de 5\% de probabilidade 38

Tabela 22. Desdobramento de lotes dentro de semanas, para $\mathrm{CT} \% \mathrm{Q}$ Minas Padrão

Tabela 23. Desdobramento para regressões nas semanas, para $\mathrm{CT} \% \mathrm{Q}$ Minas Padrão

Tabela 24. Análise de variância para extrato seco \% queijo Minas Padrão

Tabela 25. Médias de extrato seco \% queijo Minas Padrão e teste de Tuckey ao nível de $5 \%$ de probabilidade

Tabela 26. Desdobramento de lotes dentro de semanas, para ES\%Q Minas Padrão 42

Tabela 27. Desdobramento para regressões nas semanas, para ES\%Q 
Minas Padrão

Tabela 28. Correlações entre parâmetros estudados para o queijo Minas

Padrão 43 


\section{LISTA DE APÊNDICE}

Tabela A1. Acidez titulável para o Queijo Minas Frescal ...................... 52

Tabela A2. Carboidratos Totais \% Queijo Minas Frescal ........................ 52

Tabela A3. Extrato Seco \% Queijo Minas Frescal .................................. 53

Tabela A4. Acidez titulável para Queijo Minas Padrão ............................ 53

Tabela A5. Carboidratos Totais para o Queijo Minas Padrão ................... 54

Tabela A6. Extrato Seco \% Queijo Minas Padrão ……………………….... 54 


\title{
VARIAÇÃO DO TEOR DE \\ CARBOIDRATOS TOTAIS EM QUEIJOS \\ MINAS FRESCAL E MINAS PADRÃO
}

\author{
Autora: Eloisa CASTEllucci CARUSO \\ Orientador: Prof. Dr. ANTONIO JOAQUIM DE OlIVEIRA
}

\section{RESUMO}

Neste trabalho, queijos Minas Frescal e Minas Padrão, foram analisados para seus teores de carboidratos totais utilizando-se a metodologia descrita por Acton (1977), e para a acidez em gramas de ácido lático por $100 \mathrm{~g}$ de queijo, segundo o LANARA (1981). Os queijos pertenciam a três lotes distintos e foram analisados três queijos por lote, a intervalos de uma semana e durante quatro semanas seguidas. A metodologia utilizada para a determinação dos carboidratos totais mostrouse adequada para os queijos analisados, com porcentagens de recuperação de lactose, adicionada a amostras de queijos, de 99,1 a 103,7\%. Os resultados obtidos para o queijo Minas Frescal mostraram uma acidez inicial, nos queijos com dois dias de fabricação, variando entre 0,08 a $0,35 \mathrm{~g}$ ác. lático/100g de queijo e acidez ao final das quatro semanas entre 0,21 a $0,62 \mathrm{~g}$ ác. lático/100g de queijo. Para o teor de carboidratos totais, esses queijos apresentaram valores decrescentes no transcorrer das semanas, 
variando de 2,36 a $2,82 \%$ no início, para 0,47 a $1,02 \%$ ao final das quatro semanas. A correlação entre acidez e porcentagem de carboidratos totais apresentou um valor para $\mathrm{R}$ igual a $-0,7943^{* * *}$. Para os queijos Minas Padrão, a acidez variou de 0,37 a $0,47 \mathrm{~g}$ de ác. lático/ $100 \mathrm{~g}$ de queijo, no inicio, e de 0,31 a $0,56 \mathrm{~g}$ de ác. lático/100g de queijo, no final das quatro semanas. Para o teor de carboidratos, a variação foi de 0,11 a $0,18 \%$, no início, e de 0,09 a $0,12 \%$, na última semana. Neste caso não houve correlação significativa entre acidez e teor de carboidratos.

PALAVRAS-CHAVE: Carboidratos, Queijos, Lactose, Acidez. 


\title{
VARIATION IN TOTAL CARBOHYDRATES \\ CONCENTRATION OF' 'MINAS FRESCAL' \\ AND 'MINAS PADRÃO' CHEESES
}

\author{
Author: Eloisa CASTELluCCI CARUSO \\ Adviser: Prof. Dr. Antonio JoAQuim De OliveIRA
}

\section{SUMMARY}

This work evaluated total carbohydrates concentration applying the methodology described by Acton (1977) and acidity methodology (g lactic acid/100g) of LANARA (1981) to 'Minas Frescal' and 'Minas Padrão' cheeses. The experiment was studied in split-plot design, containing three parcels with three cheese samples each one. Those cheeses were weekly analyzed during four weeks $(0,7,14,21$, and 28 days). The Acton (1977) methodology showed high accuracy to both cheeses. The lactose recovery index was between 99.1 and $103.7 \%$. The acidity values for 'Minas Frescal' cheese ranged between .08 and $.35 \mathrm{~g}$ lactic acid $/ 100 \mathrm{~g}$ cheese and between .21 and $.62 \mathrm{~g}$ lactic acid/100g cheese at the first and $28^{\text {th }}$ days, respectively. The total carbohydrate concentration for 'Minas Frescal' cheese decreased with weeks, varying between 2.36 up to $2.82 \%$ at first day and .47 up to $1.02 \%$ at the end of the fourth week. The correlation between acidity and total carbohydrates concentration was negatively high $(r=$ 
$-.7943 ; \mathrm{P}<.001)$ for 'Minas Frescal' cheese. In contrast, the acidity values for 'Minas Padrão' cheese were higher and had lower variation along weeks. The values were between .37 and $.47 \mathrm{~g}$ lactic acid/100g cheese at the first day analysis and between .31 and $.56 \mathrm{~g}$ lactic acid $/ 100 \mathrm{~g}$ cheese at the $28^{\text {th }}$ day. Unlike 'Minas Frescal' cheese, the total carbohydrates for 'Minas Padrão' showed lower values and lower variation. Initial values ranged between .11 and .18\%, and at the end of fourth week ranged between .09 and $.12 \%$. In this case, the correlation between acidity and total carbohydrates concentration was not significant.

KEYWORDS: Carbohydrates, cheeses, lactose, acidity. 


\section{INTRODUÇÃO}

Nos dias atuais, cada vez mais, a qualidade vem sendo considerada a chave para o sucesso em qualquer ramo de atividade. Quando se trata da fabricação do queijo, produto passível de sofrer alterações em sua composição durante o período de maturação e de comercialização, é importante que sua qualidade mantenha-se dentro de limites que não o descaracterize e permita ao consumidor ter à sua disposição um produto confiável.

De acordo com Scott (1991), durante a transformação do leite em queijo, um dos principais aspectos a se considerar é a manutenção, no maior nível possível, das qualidades nutritivas do leite no novo produto. Entretanto, durante a elaboração do queijo, a lactose que é um componente importante do ponto-de-vista energético, tem sua concentração bastante reduzida, pois, uma grande parte dela se perde com o soro e, outra, se converte em ácido lático durante a maturação e amazenagem. Assim, queijos de maturação média ou mais longa, apresentam teores bastante baixos de lactose, ao contrário das variedades frescas não maturadas, ou de maturação muito branda, que podem apresentar apreciáveis quantidades deste carboidrato. 
O processo de maturação dos queijos é bastante complexo e, à vista da subjetividade dos resultados da avaliação sensorial por juízes ou painéis de degustadores, vários índices tem sido desenvolvidos para previsão da qualidade do queijo quando ele é colocado à disposição do consumidor. Entre os índices químicos para essa avaliação, incluí-se a destruição da lactose.

Assim, a determinação de lactose em queijos, tanto para índice de qualidade como para quantificação energética e da composição do produto, tem sido objeto de constante investigação, principalmente com relação à metodologia de análise.

Neste trabalho, o objetivo foi a determinação do teor de carboidratos residuais, expressos como lactose, nos queijos tipo Minas Frescal e Minas Padrão, comumente encontrados no comércio à disposição do consumidor. Essa determinação visa um melhor conhecimento da composição desses queijos no que diz respeito a esse componente e, se possível, correlacionálo com o tempo de armazenagem e qualidade do produto, principalmente, sob o aspecto da acidez. 


\section{REVISÃO DA LITERATURA}

\subsection{Introdução}

O queijo é um alimento bastante popular e que vem sendo consumido pelos povos há milhares de anos, embora ainda não esteja perfeitamente definido o local onde originou a sua fabricação, mas Chandler (1958), citado por Bonassi (1973), admite que essa origem tenha ocorrido na Arábia.

Até o final do século passado, a fabricação de queijos tinha um caráter doméstico, iniciando-se a sua industrialização entre 1880 e 1900 e, como consequência, a partir dessa época essa atividade vem mostrando um considerável desenvolvimento tecnológico (Davis, 1965). De acordo com Rasmussen (1979), os egípcios, gregos e todo o Império Romano, já elaboravam vários tipos de queijos bem definidos como, por exemplo, o tipo Emmental, que foi produzido na Suíça no ano 58 a.C., por influência da invasão romana. Até por volta do início da década atual, a literatura citava cerca de dois mil nomes distintos que se aplicavam ao queijo e, periodicamente, aparecem novos nomes para identificar novas variedades (Scott, 1991). 


\subsection{Importância da lactose no queijo}

Em um trabalho de pesquisa desenvolvido por Karahadian e Lindsay (1987), visando uma melhor compreensão dos fatores relacionados com o desenvolvimento da textura em queijos Brie, os autores observaram que há, inicialmente, a formação de ácido lático a partir da fermentação da lactose existente no queijo e, consequentemente, ocorre um abaixamento do valor do $\mathrm{pH}$. Verificaram que esse ácido lático, a seguir, passa a ser consumido na superficie pela ação da microflora aí existente nesse tipo de queijo, criando condições para a atuação das espécies proteolíticas com liberação de amônia e, verificaram também, que ocorre uma migração de amônia para o interior do queijo e do ácido lático do interior para a superfície. Segundo os autores, há o estabelecimento de um processo dinâmico de assimilação, formação e translocação de compostos, envolvendo a lactose e que contribui para o desenvolvimento e alterações da textura do queijo Brie.

Em um trabalho de revisão, Farkye \& Fox (1990) fizeram várias colocações bastante elucidativas, algumas delas focalizando a importância da quantificação da lactose em queijos. Segundo esses autores, os resultados da avaliação sensorial dos queijos são subjetivos, e vários índices mais objetivos tem sido desenvolvidos e utilizados para a previsão da qualidade do queijo no momento de sua colocação à disposição do consumidor. Entre os índices químicos para essa avaliação os autores incluem a degradação da lactose, ressaltando o fato de que a concentração residual desse açúcar na massa de queijo depende do método de fabricação, do tempo e atividade das culturas inoculadas, e especialmente da 
concentração de sal na fase líquida.

A importância da lactose sobre certas propriedades dos queijos foi observada em trabalhos de Kombila-Moundounga \& Lacroix (1991), os quais, estudando o efeito da lactose, cloreto de sódio e glicerol sobre as propriedades reológicas e coloração dos queijos, verificaram que aqueles componentes influenciaram substancialmente estes parâmetros, tendo a lactose mostrado efeito interativo com o cloreto de sódio nessas alterações, além de, isoladamente, afetar a coloração do produto final.

A determinação da lactose em queijos tem sido objeto de investigação por diferentes autores, para os mais variados tipos de queijos. Os trabalhos tem estado mais dirigidos para a metodologia da análise embora, geralmente, apresentando resultados de sua aplicação em queijos.

\subsection{Metodologia da análise}

Diferentes autores tem apresentado vários métodos para a determinação de lactose em queijos e outros produtos lácteos. Alguns desses métodos tem se mostrado bastante apropriados para utilização em trabalhos de pesquisa e são geralmente baseados em colorimetria, oxiredutimetria (gravimétrica e titulométrica) e na ação de enzimas.

É importante ressaltar-se o fato de que, na proposição de novas metodologias, vários autores referem-se à lactose como o único carboidrato determinado nos queijos, mesmo quando se utilizam de reagentes específicos para carboidratos totais, tais como, a antrona, o fenol e outros, desconsiderando a presença e interferência de galactose e glucose, produtos 
do desdobramento da lactose, presentes na maioria dos casos de produtos de laticínios que sofrem a ação de microrganismos durante sua elaboração. Assim, nesta revisão, respeitou-se a terminologia utilizada pelos autores, mesmo acreditando ser mais correto utilizar o termo carboidratos totais no lugar de lactose.

De acordo com Fagen et al. (1954), o primeiro pesquisador a utilizar a antrona para a detecção de carboidratos foi Dreywood em 1946, utilizando preparações sintéticas, mas, trabalhos posteriores comprovaram a viabilidade de aplicação dessa metodologia também para materiais biológicos, inclusive com atenção para possível interferência de outros materiais presentes. Assim, tendo em vista as evidências de que material não carboidratos, presentes nos produtos láteos, podem ser considerados não interferentes com respeito ao reagente antrona. Fagen et al. (1954) apresentaram um método colorimétrico sensível e rápido para determinação da lactose em leite integral, em queijos e nos sólidos secos não gordurosos do leite. Os resultados obtidos mostraram-se bastante satisfatórios quando comparados aos obtidos com o método baseado na redução do ferro e indicado pela AOAC (1950) ${ }^{1}$. Os testes para verificação de recuperação de lactose adicionada às diferentes amostras apontaram uma recuperação de $98 \%$ no leite integral, $100 \%$ nos sólidos não gordurosos do leite e de 94 a $97 \%$ nos queijos.

Durante o estudo da maturação de alguns queijos regionais, Barnett \& Tawab (1957), tiveram necessidade de determinar o teor de lactose em leite e queijos, e, por considerarem o método oficial (na época,

1 ASSOCIATION OF OFFICIAL AGRICULTURAL CHEMISTS. Official and Tentative Methods of Analysis, $7^{\mathrm{a}}$ ed., p. 163, 506-507, 1950. 
AOAC, 1945) muito trabalhoso, e o de Fagen et al. (1954) pouco prático devido à instabilidade do reagente antrona, desenvolveram uma metodologia rápida e prática, baseada no método de Dubois et al. (1956). Nesse método, o reagente utilizado foi o fenol-ácido sulfúrico que, sob as mesmas condições experimentais, apresenta leituras colorimétricas muito similares para quantidades equivalentes de diferentes carboidratos. Como o trabalho estava relacionado com os carboidratos do leite e do queijo, Barnett e Tawab utilizaram a lactose como padrão e os resultados foram expressos como esse açúcar. Comprovaram também, que outros componentes principais do leite e queijos não interferem nos resultados, dentro das concentrações utilizadas, de zero a $100 \mu \mathrm{g}$ de lactose $/ 2 \mathrm{ml}$ do extrato final utilizado. Nos testes de recuperação de lactose adicionada, os valores mínimo e máximo de recuperação obtidos foram de 102\% e 95\%, respectivamente.

Ao realizar uma extensa série de análises em leite humano, Lawrence (1968) utilizou o método do fenol-ácido sulfúrico de acordo com Marier \& Boulet (1959), porém, com a alternativa de adição de 1,0ml de uma solução de fenol a 5\%. Essa alternativa, já mencionada por Dubois et al. (1956) e não considerada por outros autores, veio a corrigir um sério problema que era a adição de $0,1 \mathrm{ml}$ de uma solução altamente viscosa de fenol a $89 \%$ e que vinha sendo causa de variações indesejáveis nos resultados. Segundo o autor, o método mostrou-se bastante seguro e foi utilizado para vários produtos de laticínios.

Em um trabalho sobre a hidrólise de lactose em produtos lácteos, Nickerson et al. (1976) tiveram necessidade de desenvolver uma 
metodologia que permitisse a detecção de lactose na presença dos produtos de sua hidrólise, glucose e galactose. Para isso, utilizaram a reação com metilamina em solução alcalina a quente, e, estabeleceram as condições necessárias para o desenvolvimento do método. Nos testes realizados, a recuperação de lactose apresentada pelo método esteve entre 93,7 e $102,5 \%$, considerada muito boa pelos autores.

Com o objetivo de desenvolver um método rápido para avaliação de lactose em queijos, Acton (1977) dirigiu sua atenção para o método do fenol-ácido sulfúrico inicialmente proposto por Barnett \& Tawab (1957) e modificado por Marier \& Boulet (1959) e por Lawrence (1968), e, com base nos resultados obtidos, estabeleceram as alterações necessárias para utilizá-lo com melhor precisão na determinação de carboidratos em queijos. Com a aplicação do método, devidamente modificado, o autor encontrou valores médios de recuperação de lactose, previamente adicionada às amostras, ao redor de $98 \%$, variando de 94,9 a $101,7 \%$ e, para uma série de determinações em queijo Cheddar, uma concentração média de 0,24 +/$0,018 \%$ de carboidratos, expressos como lactose.

\subsection{Variação do teor de lactose}

Em um trabalho sobre a composição média dos queijos Prato e Minas, à disposição dos consumidores no mercado brasileiro, Furtado \& Lourenço Neto (1979) apresentaram resultados que demonstraram grande variação em alguns parâmetros desses queijos o que os levou a concluirem que, face à falta de padrões legais mínimos, assiste-se a uma progressiva 
descaracterização desses produtos, em especial o queijo Minas. Dentre os resultados apresentados, o valor do extrato seco para o queijo tipo Minas Padrão variou entre 52,13 e $60,22 \%$ e para o tipo Prato esse parâmetro ficou entre 54,30 e $63,30 \%$; quanto ao $\mathrm{pH}$, o queijo Minas apresentou valores entre 4,30 e 5,40 e o Prato, valores entre 5,00 e 5,70.

Dolezalek et al. (1981), investigaram a fermentação da lactose em queijos dos tipos Camembert, Gouda e Emmental, com vistas ao processo de maturação e de qualidade final do produto. Para o queijo Camembert, elaborado a partir de leite contendo $4,18 \%$ de lactose, verificaram que o principal momento da fermentação da lactose ocorreu durante a drenagem e enformagem dos queijos, quando o teor de lactose caiu para $1,32 \%$, com correspondente aumento da acidez, e o consumo desse açúcar prosseguiu lentamente de tal forma que, após 6 dias, ainda $0,53 \%$ de lactose foi detectado no queijo e, no momento da expedição dos queijos, aos 14 dias, ainda apresentava valores ao redor de $0,1 \%$ de lactose. Para o queijo tipo Gouda, partindo de um leite com 4,13\% de lactose, esta foi totalmente consumida durante o período de pré-maturação, que termina no momento da salga do queijo. No caso do queijo tipo Emmental, também houve um rápido consumo de lactose e, após um período de três dias de salga, ou seja, no primeiro dia de maturação, o teor de lactose já era apenas de $0,06 \%$, entretanto, apresentava um teor de $0,53 \%$ de D-galactose, o que não foi detectado nos queijos tipo Camembert e tipo Gouda.

Thomas \& Pearce (1981), estudaram o efeito do sal na fermentação da lactose e na proteólise do queijo Cheddar, variando a concentração de sal dentro da faixa de 4 a $6 \%$, que cobre os valores comumente encontrados para esse tipo de queijo. Os resultados obtidos 
confirmaram o efeito inibitório do sal na fermentação da lactose, pois, os queijos com $6 \%$ de sal apresentaram um teor de lactose residual de $0,57 \%$ aos 14 dias de fabricação e até $0,25 \%$ após 180 dias, enquanto que, para os queijos com $4 \%$ de sal, após 14 dias a lactose já havia sido quase completamente utilizada, com um residual de apenas 0,09\%.

Segundo Furtado (1983), diversas tentativas tem sido feitas para levar à padronização do queijo Minas, já que há um consenso tanto sobre a importância deste queijo a nível nacional como sobre a grande variedade de tipos similares no mercado com a denominação comum de "Minas". Nas diversas proposições já feitas e apontadas pelo autor, os principais parâmetros estão nas faixas seguintes: umidade, 35,85 a 42,29\%; gordura, 26,8 a $32,0 \%$; proteínas, 22,97 a $32,03 \%$ e acidez, 0,59 a $1,60 \%$. Por diferença, o teor de lactose seria de 1,6 a 2,8\%.

Utilizando a cromatografia líquida, Pollman (1984) analisou 40 peças de queijos dos tipos Romano e Parmesão, autênticas, não adulteradas, e encontrou todos os valores de lactose \% queijo dentro da faixa de zero a $1 \%$. Determinou, também, os valores para as relações $\mathrm{Ca} / \mathrm{P}$ e $\mathrm{Ca} / \mathrm{Mg}$ em 74 queijos não adulterados, principalmente dos tipos Parmesão e Romano mas, incluiu também os tipos Gruyere, Provolone e Mozzarella, encontrando valores médios, para aquelas relações, de 1,55 e 23,3, respectivamente. Assim, com base nos resultados obtidos, concluiu que pode-se suspeitar de adulteração em queijos ralados que apresentem relações $\mathrm{Ca} / \mathrm{P}$ e $\mathrm{Ca} / \mathrm{Mg}$ e teor de lactose ou, mesmo, apenas o teor de lactose, fora das faixas por ele determinadas.

Wolfschoom-Pombo et al. (1984), estudando as alterações que ocorrem no queijo Minas Frescal durante o período de armazenamento, 
procederam a 9 fabricações desse tipo de queijo segundo a técnica de fabricação que utiliza ácido lático, e, de cada lote, foram retiradas amostras após 1, 6, 9 e 14 dias de fabricação e analisadas para $\mathrm{pH}$, acidez, lactose, umidade e sal. Dentre as correlações obtidas para os diferentes parâmetros pesquisados, os autores obervaram que o teor de lactose residual é função também da umidade do queijo, além da atividade da cultura lática e, esse teor foi fator determinante na vida de prateleira do queijo, pois, verificaram que as mudanças de $\mathrm{pH}$, ou elevação da acidez, que ocorrem a partir do $6^{\circ}$ dia, estão correlacionadas positivamente com o acúmulo de substâncias nitrogenadas, resultantes de transformações das proteínas, e que são fatores preponderantes na perda das características organolépticas que caracterizam o produto para o consumo.

Em um trabalho realizado por Wolfschoon-Pombo et al. (1986), os autores procederam a 6 fabricações de queijo Minas Padrão, numa pesquisa orientada para a procura de melhores conhecimentos sobre as interações físico-químicas que ocorrem, desde o momento em que o leite é colocado no tanque, até a retirada do queijo da salmoura, levando em conta, entre outros fatores, a degradação da lactose. Segundo os dados apresentados, o teor inicial de lactose no leite utilizado era de 4,92 +/$0,16 \%$, decrescendo para $1,52+/-0,62 \%$ após a salga, apresentando o maior declínio durante a prensagem e salga. Para a acidez, expressa em \% de ácido lático, em peso, no queijo, o seu valor no leite era de $0,29+/-0,01$, aumentando para $1,86+/-0,19$ após a salga e, a porcentagem de extrato seco, nesse mesmo período, aumentou de $12,02+/-0,25$ no leite, para $50,64+/-2,03$ no queijo após a salga.

Bouzas et al. (1991) estudando as alterações químicas que 
ocorrem no queijo Cheddar durante o período de armazenamento de 0 a 100 dias e a diferentes temperaturas, até $35^{\circ} \mathrm{C}$, notaram que o consumo de lactose e a formação de ácido lático foram afetados significativamente pelo período de armazenamento mas, não sofreram influência da temperatura.

A possibilidade de adulteração em queijos Parmesão ralado, pela adição de soro sêco de queijo, levou Blais \& Vailhen (1995) a testar uma série de 32 amostras daquele queijo para o seu teor de lactose utilizando-se do método enzímico proposto por Blais $(1993)^{2}$ que, foi inicialmente desenvolvido para aplicação em soluções padrões. O critério adotado pelos autores foi baseado em Pollman (1984) pelo qual, amostras com teor acima de $1 \%$ de lactose, foram consideradas adulteradas. Assim, para as 32 amostras analisadas, 25 foram consideradas adulteradas segundo esse critério, estando as outras 5 entre 0 e $1 \%$ de lactose, faixa essa considerada normal para o queijo parmesão.

\footnotetext{
${ }^{2}$ BLAIS, B. W. An automated microassay for lactose in foods employing a simple and inexpensive enzymatic detection system. Microbiologie Aliments Nutrition, v.11, p. $43-49,1993$.
} 


\section{MATERIAL E MÉTODOS}

\subsection{Queijo Minas Frescal}

As peças inteiras do queijo Minas Frescal utilizadas neste trabalho, todas elas da mesma marca e pesando por volta de seiscentos gramas, foram adquiridas no comércio de Piracicaba, SP, e, compradas sempre aos dois dias de sua fabricação. Em três semanas distintas, foram adquiridos nove queijos, sendo três em cada semana num mesmo dia, representando, assim, três diferentes lotes de fabricação com três amostras para cada um deles. Durante todo o transcorrer das análises, os queijos, embalados em sacos plásticos e com retirada do ar, foram mantidos em refrigerador tipo doméstico, a uma temperatura ao redor dos $7,0+/-1,5^{\circ} \mathrm{C}$.

\subsection{Queijo Minas Padrão}

O mesmo critério adotado para a aquisição do Queijo Minas Frescal foi empregado para o queijo Minas Padrão, entretanto, a marca deste era diferente, as peças apresentavam peso médio ao redor de um quilo e duzentos gramas e foram adquiridas com tempo de fabricação entre 21 e 
23 dias. Os queijos foram mantidos no mesmo refrigerador e à mesma temperatura, ao redor $\operatorname{dos} 7,0+/-1,5^{\circ} \mathrm{C}$.

\subsection{Preparo das amostras para as análises}

As amostras de cada queijo foram retiradas com o trado sonda $\mathrm{e}$ procurou-se sempre coletar porções representativas de várias partes do queijo para compor a amostra, com 28 a 30 gramas, suficiente para as análises do dia. A seguir, a amostra foi triturada com o auxílio de uma espátula, homogeneizada e, então, separadas as sub-amostras para as diferentes análises.

\subsection{Análises fisico-químicas}

\subsubsection{Frequência das análises}

Os queijos foram analisados quanto ao seu teor de carboidratos totais, umidade, extrato seco total e acidez titulável, para $0,1,2,3$ e 4 semanas de armazenagem, com início no dia de sua aquisição.

\subsubsection{Carboidratos totais}

O método utilizado para a determinação do teor de carboidratos 
totais foi o descrito por Acton (1977), baseado na dispersão da amostra em água, clarificação pela adição de hidróxido de sódio $0,5 \mathrm{~N}$ e solução de sulfato de zinco heptaidratado a $10 \%(\mathrm{~m} / \mathrm{v})$, seguido de filtração e determinação, em triplicata, dos carboidratos totais no filtrado, pelo método fenol-sulfúrico sugerido por Lawrence (1968). Os resultados foram expressos como lactose, pois, esse foi o açúcar utilizado como padrão nas determinações.

\subsubsection{Extrato seco}

De acordo com o LANARA (1981), para o teor de extrato seco no queijo (ES \% Q) foi, primeiramente, determinada a umidade por secagem da sub-amostra em estufa a $85^{\circ} \mathrm{C}$, até peso constante. $\mathrm{O}$ extrato seco foi, então, calculado segundo a fórmula:

ES \% Q $=100$ - Umidade \% queijo

As análises foram efetuadas em triplicata para cada amostra.

\subsubsection{Acidez titulável}

Para esta análise, dez gramas da amostra preparada foram submetidos a uma extração, em gral de porcelana, com $100 \mathrm{ml}$ de água destilada. Da suspensão obtida, uma alíquota de $50 \mathrm{ml}$ foi utilizada para titulação com $\mathrm{NaOH} 0,1 \mathrm{~N}$, utilizando-se uma solução de fenolftaleína a $1 \%$ como indicador, conforme metodologia descrita pelo LANARA (1981). 


\subsection{Análise estatística}

O delineamento experimental adotado, para cada um dos dois tipos de queijo, foi o de parcelas subdivididas no tempo ( "split plot"), conforme o esquema seguinte:

\begin{tabular}{lc}
\hline C. Variação & GL \\
\hline Lotes ( L ) & 2 \\
Resíduo ( a ) & 6 \\
\hline (Parcelas ) & $(8)$ \\
\hline Semanas ( S ) & 4 \\
Interação L x S & 8 \\
Resíduo ( b ) & 24 \\
\hline Total & 44 \\
\hline
\end{tabular}

Foi feita análise de correlação entre carboidratos totais \% queijo (CT\%Q) e acidez (\%AC), e também entre semanas e Ac\%Q, CT\%Q e $\mathrm{ES} \% \mathrm{Q}$, para os dois tipos de queijos estudados. 


\subsection{Recuperação da lactose}

\subsubsection{Com variação da quantidade de lactose adicionada}

A partir de um queijo Minas Frescal contendo 2,055\% de lactose, foi obtido um extrato filtrado, conforme metodologia descrita por Acton (1977) e, então, cinco alíquotas de $5 \mathrm{ml}$, cada uma, foram transferidas para balões volumétricos de $100 \mathrm{ml}$ de capacidade aos quais, foram adicionados respectivamente, $0,2,4,6$ e $8 \mathrm{ml}$ de uma solução de lactose monoidratada contendo $489 \mu \mathrm{g} / \mathrm{ml}$, obtida por diluição de uma solução estoque de $0,489 \mathrm{~g} / 100 \mathrm{ml}$. Após o volume dos balôes serem completados com água destilada, um mililitro de cada solução foi utilizado para determinação da lactose, conforme o método descrito por Lawrence (1968).

\subsubsection{Sem variação da quantidade de lactose adicionada}

Para este teste foram utilizados o mesmo extrato filtrado e a mesma solução de lactose diluida, utilizados no primeiro teste (item 3.6.1). Em cinco balões volumétricos de $100 \mathrm{ml}$ de capacidade, foram colocados, respectivamente, $0,2,4,6$, e $8 \mathrm{ml}$ do extrato diluído e, em todos os balões, $5 \mathrm{ml}$ da solução contendo $489 \mu \mathrm{g}$ de lactose monoidratada por mililitro. Os volumes foram completados a $100 \mathrm{ml}$ com água destilada e, de cada um, retiradas alíquotas de $1 \mathrm{ml}$ para a determinação de lactose, utilizando-se o método descrito por Lawrence (1968). 


\subsubsection{Com adição da lactose antes da clarificação}

Para o preparo das soluções utilizadas no teste de recuperação da lactose, quando se adiciona a lactose antes do processo de clarificação do extrato, foi utilizada uma amostra do queijo Minas Frescal pesando cerca de $15 \mathrm{~g}$ e com um teor de $1,689 \%$ de lactose. Essa amostra foi desfeita e homogeneizada completamente com o auxílio de pistilo e grau de porcelana. A seguir, com a maior exatidão possivel, foram pesadas quatro sub-amostras de $2,0 \mathrm{~g}$ cada uma, às quais foram adicionados, respectivamente, $0,5,10$ e $15 \mathrm{ml}$ de uma solução contendo $39,36 \mu \mathrm{g}$ de lactose monoidratada por mililitro. Para as quatro sub-amostras foi procedido normalmente conforme o método de Acton (1977), mas, com o volume final completado a $200 \mathrm{ml}$, em seguida filtrado e diluído $1: 10 \mathrm{e}$, então utilizadas alíquotas de $1 \mathrm{ml}$ para a determinação de lactose conforme metodologia apresentada por Lawrence (1968). 


\section{RESULTADOS E DISCUSSÃO}

\subsection{Recuperação da lactose}

Nas Tabelas 1, 2 e 3, estão os resultados obtidos nos testes realizados para se determinar a porcentagem de recuperação de lactose adicionada, utilizando-se a mesma metodologia de análise empregada durante o transcorrer deste trabalho.

Os resultados obtidos no primeiro teste e expressos na Tabela 1 , mostram recuperações de $100 \%$, ou muito próximas disso, para valores de lactose adicionada até $19,56 \mu \mathrm{g} / \mathrm{ml}$, correspondendo a um total de $40,11 \mu \mathrm{g} / \mathrm{ml}$ e, para os valores acima desses, embora as recuperações também tenham sido muito boas, passaram a mostrar uma tendência de elevação.

Com o intuito de verificar se esse fato ocorreu mesmo devido ao aumento de lactose adicionada, em função da qual é calculada a porcentagem de recuperação, foi realizado um segundo teste mantendo-se constante a lactose adicionada e, através de diluições adequadas, aumentando-se progressivamente a quantidade de lactose presente a partir do queijo. Pelos resultados deste teste, apresentados na Tabela 2, nota-se 
Tabela 1. Recuperação de lactose ${ }^{1}$ pelo método fenol-ácido sulfúrico.

\begin{tabular}{cccccc}
\hline Do queijo & Adicionada & Calculada & Determinada & \multicolumn{2}{c}{ Recuperação } \\
\cline { 5 - 6 } & & & & \multicolumn{1}{c}{$\%$} & faixa \\
\hline 20,55 & 0,00 & 20,55 & 20,55 & \multicolumn{1}{c}{$-\ldots$} & $\cdots$ \\
20,55 & 9,78 & 30,33 & 30,33 & 100,0 & 99,2 a 101,0 \\
20,55 & 19,56 & 40,11 & 39,95 & 99,2 & 99,0 a 99,7 \\
20,55 & 29,34 & 49,89 & 50,42 & 102,6 & 102,1 a 103,5 \\
20,55 & 39,12 & 59,67 & 60,31 & 103,1 & 102,2 a 104,0 \\
\hline
\end{tabular}

${ }^{1}$ - Quantidades de lactose expressas em $\mu \mathrm{g} / \mathrm{ml}$.

um comportamento similar ao do teste anterior, o que permite acreditar que o fator determinante para o aumento na porcentagem de recuperação da lactose é a quantidade total de lactose presente em $1 \mathrm{ml}$ utilizado para a análise.

Tabela 2. Recuperação de lactose ${ }^{1}$ pelo método fenol-ácido sulfúrico.

\begin{tabular}{cccccc}
\hline Do queijo & Adicionada & Calculada & Determinada & \multicolumn{2}{c}{ Recuperação } \\
\cline { 5 - 6 } & & & & $\%$ & faixa \\
\hline 0,0 & 24,45 & 24,45 & 24,45 & 100,0 & -- \\
8,21 & 24,45 & 32,66 & 32,82 & 100,7 & 99,5 a 101,7 \\
16,42 & 24,45 & 40,87 & 41,05 & 100,7 & 99,3 a 101,8 \\
24,64 & 24,45 & 49,09 & 49,62 & 102,2 & 100,2 a 104,1 \\
32,85 & 24,45 & 57,30 & 58,04 & 103,0 & 101,6 a 105,0 \\
\hline
\end{tabular}

- Quantidades de lactose expressas em $\mu \mathrm{g} / \mathrm{ml}$.

Um terceiro teste foi relizado para se observar o efeito da clarificação do extrato sobre a recuperação da lactose e os resultados encontram-se na Tabela 3. Pelos dados apresentados verifica-se que, 
praticamente, a recuperação da lactose não se alterou com a clarificação por adição de hidróxido de sódio e sulfato de zinco, com posterior filtração do extrato.

Tabela 3. Efeito da clarificação sobre a recuperação da lactose ${ }^{1}$.

\begin{tabular}{cccccc}
\hline Do queijo & Adicionada & Calculada & Determinada & \multicolumn{2}{c}{ Recuperação } \\
\cline { 5 - 6 } & & & & \multicolumn{1}{c}{$\%$} & faixa \\
\hline 16,89 & 00,00 & 16,89 & 16,89 & -- & -- \\
16,89 & 09,84 & 26,73 & 26,80 & 100,7 & 99,8 a 101,7 \\
16,89 & 19,68 & 36,57 & 36,46 & 99,0 & 99,0 a 100,2
\end{tabular}

- Quantidades de lactose expressas em $\mu \mathrm{g} / \mathrm{ml}$.

De acordo com os dados apresentados, para os três testes, a recuperação de lactose variou dentro de uma faixa de porcentagens de 98,61 a $103,10 \%$, bem mais estreita do que aquelas encontradas na literatura para os trabalhos de Barnett \& Tawab (1957), Nickerson et al. (1976) e Acton (1977), que foram 95,0 a $102,0 \%, 93,7$ a $102,5 \%$ e 94,9 a $101,7 \%$, respectivamente. Os valores mínimos estão bem mais próximos de $100 \%$ do que aqueles citados na literatura, enquanto que, os máximos estão muito pouco acima.

Diante dessas observações, em todas as análises de lactose realizadas no transcorrer deste trabalho, procedeu-se, sempre que necessário, a uma diluição do extrato do queijo para ajustar sua concentração para valores inferiores a $40 \mu \mathrm{g}$ de lactose $/ \mathrm{ml}$, antes da análise. 


\subsection{Queijo Minas Frescal}

Os valores médios para cada um dos três lotes, no transcorrer das quatro semanas, para acidez titulável, carboidratos totais e extrato seco \% queijo, encontram-se nas Tabelas 5, 9 e 12, respectivamente.

Para o queijo Minas Frescal, os resultados das análises de cada queijo, em separado, encontram-se nas Tabelas A1, A2 e A3, do Apêndice.

\subsubsection{Acidez titulável}

Para os valores de acidez titulável, os resultados da análise de variância, apresentados na Tabela 4 , mostram que existe pelo menos um contraste significativo ao nível de $1 \%$ entre os comportamentos dos 3 lotes, de acordo com o valor encontrado para $F$, quando a causa de variação foi lotes (L).

Essa diferença de comportamento foi comprovada pelo teste de Tuckey, quando aplicado às médias para o total das semanas de cada lote e cujos resultados são apresentados na Tabela 5 , que contém os valores médios de $\mathrm{Ac} \% \mathrm{Q}$ entre os três queijos de cada lote, nas semanas 0 a 4 , e no total das semanas. Pelos valores das médias, para o total das semanas em cada lote, e do valor da DMS, conclui-se que o lote 1 diferiu significativamente dos lotes 2 e 3 , e estes, não apresentaram diferença significativa entre si, para o total das semanas. 
Tabela 4. Análise de variância para acidez titulável nos queijos Minas Frescal.

\begin{tabular}{lcccc}
\hline \multicolumn{1}{c}{ C. Variações } & G.L. & S.Q. & Q.M. & F \\
\hline Lotes (L) & 2 & 0,48808 & 0,244042 & $82,36^{* * *}$ \\
Resíduo (a) & 6 & 0,01778 & 0,002963 & \\
\hline (Parcelas) & $(8)$ & $(0,50586)$ & & \\
\hline Semanas (S) & 4 & 0,52322 & 0,130804 & $140,50^{* * *}$ \\
Int. L x S & 8 & 0,02682 & 0,003352 & $3,59^{* * *}$ \\
Resíduo & 24 & 0,02242 & 0,000934 & \\
\hline Total & 44 & 1,07832 & & \\
\hline
\end{tabular}

- Significativo ao nível de $1 \%$.

Tabela 5. Médias da acidez titulável ${ }^{1}$ em queijo Minas Frescal e teste de Tuckey $^{2}$ ao nível de $5 \%$ de probabilidade.

\begin{tabular}{cccccc|c}
\hline Lote & \multicolumn{5}{c|}{ S e m a n a s } & Média \\
\cline { 2 - 6 } & 0 & 1 & 2 & 3 & 4 & \\
\hline 1 & $0,350^{\mathrm{a}}$ & $0,393^{\mathrm{a}}$ & $0,417^{\mathrm{a}}$ & $0,470^{\mathrm{a}}$ & $0,623^{\mathrm{a}}$ & $0,451^{\mathrm{a}}$ \\
2 & $0,097^{\mathrm{b}}$ & $0,123^{\mathrm{b}}$ & $0,163^{\mathrm{b}}$ & $0,293^{\mathrm{b}}$ & $0,373^{\mathrm{b}}$ & $0,210^{\mathrm{b}}$ \\
3 & $0,083^{\mathrm{b}}$ & $0,180^{\mathrm{b}}$ & $0,263^{\mathrm{c}}$ & $0,283^{\mathrm{b}}$ & $0,470^{\mathrm{c}}$ & $0,256^{\mathrm{b}}$ \\
\hline DMS & 0,0746 & 0,0746 & 0,0746 & 0,0746 & 0,0746 & 0,061 \\
\hline
\end{tabular}

- Expressa em gramas de ácido lático/100g de queijo.

${ }^{2}$ - Letras diferentes na mesma coluna, indicam diferença significativa entre os valores.

Pela observação dos resultados da Tabela 5 nota-se, ainda, que para os três lotes a acidez aumentou com o decorrer das semanas, e, o lote que apresentou a acidez inicial mais alta, manteve sempre valores significativamente mais elevados, embora, a variação porcentual para este lote tenha sido mais baixa do que para os outros dois. 
Esse aumento da acidez com o decorrer das semanas é notado, principalmente, para queijos que não sofrem maturação e apresentam teores relativamente elevados de carboidratos totais no produto recém fabricado, como é o caso do Minas Frescal, conforme relatam vários autores, para diferentes queijos (Dolezalek et al., 1981; Wolfschoom-Pombo et al., 1986; Karahadian \& Lindsay, 1987; Farkye \& Fox, 1990; Bouzas et al., 1991 Scott, 1981)

$\mathrm{O}$ valor de $\mathrm{F}$, para a interação lotes $\mathrm{x}$ semanas (Tabela 4), significativo ao nível de $1 \%$, indica que as semanas influiram diferentemente nos comportamentos dos lotes, ou seja, cada lote variou de modo diferente, justificando verificar o comportamento dos lotes dentro de cada semana. Para isso, fez-se o desdobramento apresentado na Tabela 6 e que demonstra comportamentos diferentes, ao nível de $1 \%$ de significância, para os lotes em todas as semanas.

Tabela 6. Desdobramento de lotes dentro de semanas, para Ac\%Q Minas Frescal.

\begin{tabular}{lcccc}
\hline \multicolumn{1}{c}{ C. Variações } & G.L. & S.Q. & Q.M. & F \\
\hline Lotes dentro de semana 0 & 2 & 0,135416 & 0,067708 & $50,53^{* * *}$ \\
Lotes dentro de semana 1 & 2 & 0,120510 & 0,060255 & $44,97^{* * *}$ \\
Lotes dentro de semana 2 & 2 & 0,096408 & 0,048204 & $35,97^{* * *}$ \\
Lotes dentro de semana 3 & 2 & 0,067466 & 0,033733 & $25,17^{* * *}$ \\
Lotes dentro de semana 4 & 2 & 0,095102 & 0,047551 & $35,49^{* * *}$ \\
\hline Resíduo & 24 & & 0,001340 & \\
\hline
\end{tabular}

\footnotetext{
- Significativo ao nível de $1 \%$.
} 
Pelo teste de Tuckey (Tabela 5), na comparação dos lotes dentro de cada semana, verifica-se que essa diferença de comportamento refere-se, principalmente, ao lote 1 que diferiu significativamente, em todas as semanas, dos lotes 2 e 3 , apresentando sempre valores mais elevados. Os lotes 2 e 3 não apresentatram diferenças significativas entre si, nas semanas 0,1 e 3, mas, nas semanas 2 e 4, os 3 lotes comportaram-se diferentemente entre si.

Quando a comparação foi para as semanas, houve uma diferença significativa ao nível de $1 \%$, conforme mostra o resultado do teste $\mathrm{F}$ (Tabela 4), indicando que a acidez mostrou um comportamento médio diferente no transcorrer das semanas e, para verificar se esse comportamento segue uma tendência polinomial, foram desdobrados os GL de semanas, obtendo-se os resultados apresentados na Tabela 7.

Tabela 7. Desdobramento para regressões nas semanas, para Ac\%Q Minas Frescal.
C. Variações
G.L.
S.Q.
Q.M.
F

\begin{tabular}{llccc}
\hline Regressão Linear & 1 & 0,49404 & 0,49404 & $528,95^{* * *}$ \\
Regressão Quadrática & 1 & 0,02376 & 0,02376 & $25,44^{* * *}$ \\
Regressão Cúbica & 1 & 0,00527 & 0,00527 & $5,64^{* *}$ \\
Regressão 4ํo grau & 1 & 0,00015 & 0,00015 & 0,16
\end{tabular}

(Semanas)

(4)

$(0,52322)$

Resíduo

24

0,02242

0,000934

- Significativo ao nível de $5 \%$.

*** - Significativo ao nível de $1 \%$.

Observa-se, pelos resultados apresentados na Tabela 7, que houve um ajuste significativo de uma função polinomial até o $3^{\circ}$ grau, entretanto, a 
linear ajusta-se muito bem, como mostra o seu valor do teste $F$, bem superior aos demais.

\subsubsection{Carboidratos totais}

Os resultados da análise de variância aplicada aos valores de carboidratos \% queijo Minas Frescal, encontram-se na Tabela 8. Houve diferença significativa, ao nível de $1 \%$, entre os comportamentos dos três lotes, conforme mostra o valor de $\mathrm{F}$ para lotes.

Tabela 8. Análise de variância para carboidratos totais em queijos Minas Frescal.

\begin{tabular}{lcccc}
\hline \multicolumn{1}{c}{ C. Variações } & G.L. & S.Q. & Q.M. & F \\
\hline Lotes (L) & 2 & 1,75986 & 0,879932 & $36,84^{* * *}$ \\
Resíduo (a) & 6 & 0,14330 & 0,023884 & \\
\hline (Parcelas) & $(8)$ & $(1,90316)$ & & \\
\hline Semanas (S) & 4 & 17,28648 & 4,321619 & $316,33^{* * *}$ \\
Int. L x S & 8 & 0,20015 & 0,025019 & 1,83 \\
Resíduo & 24 & 0,32788 & 0,013662 & \\
\hline Total & 44 & 19,71767 & & \\
\hline
\end{tabular}

- Significativo ao nível de $1 \%$.

O teste de Tuckey, quando referido às médias de cada lote para o total das semanas, e cujos resultados estão na Tabela 9, comprova essa diferença mostrando que o lote 2 diferiu significativamente dos lotes 1 e 3 e estes não apresentaram diferença significativa entre si. 
Tabela 9. Médias de carboidratos totais ${ }^{1} \%$ queijo Minas Frescal e teste de Tuckey $^{2}$ ao nível de $5 \%$ de probabilidade.

\begin{tabular}{cccccc|c}
\hline Lote & \multicolumn{5}{c|}{ S e m a n a } & Média \\
\cline { 2 - 5 } & 0 & 1 & 2 & 3 & 4 & \\
\hline 1 & $2,359^{\mathrm{a}}$ & $1,952^{\mathrm{a}}$ & $1,504^{\mathrm{a}}$ & $0,918^{\mathrm{a}}$ & $0,471^{\mathrm{a}}$ & $1,441^{\mathrm{a}}$ \\
2 & $2,817^{\mathrm{b}}$ & $2,224^{\mathrm{b}}$ & $2,056^{\mathrm{b}}$ & $1,410^{\mathrm{b}}$ & $1,019^{\mathrm{b}}$ & $1,905^{\mathrm{b}}$ \\
3 & $2,358^{\mathrm{a}}$ & $1,845^{\mathrm{a}}$ & $1,647^{\mathrm{a}}$ & $1,159^{\mathrm{a}}$ & $0,766^{\mathrm{b}}$ & $1,555^{\mathrm{a}}$ \\
\hline DMS & 0,2554 & 0,2554 & 0,2554 & 0,2554 & 0,2554 & 0,1730 \\
\hline
\end{tabular}

- Expressos como lactose.

2 - Letras diferentes na mesma coluna, indicam diferença significativa entre os valores.

O comportamento dos valores de $\mathrm{CT} \% \mathrm{Q}$ durante o transcorrer das semanas, para os três lotes, revela uma nítida tendência de diminuição no teor desse componente, conforme pode-se concluir com base nos resultados apresentados na Tabela 9 para as médias entre os três queijos de cada lote, nas semanas 0 a 4 . Esse comportamento foi semelhante ao relatado por Wolfschoom-Pombo et al. (1984), também para queijo Minas Frescal. Quanto ao teor de carboidratos na semana 0 , que representa o queijo recém adquirido e com apenas dois dias de fabricação, os valores encontrados estão abaixo do máximo de $3 \%$ relatado pela Faculdade de Saúde Pública da USP (1971) e de 2,9 a 3,5\% encontrados por Wolfschoom-Pombo et al. (1984).

$O$ valor de $F$ para a interação lotes $x$ semanas, apresentado na Tabela 8 , não foi significativo até ao nível de $10 \%$, indicando não ter havido diferença significativa, até esse nível, para os comportamentos dos lotes nas semanas. Entretanto, o teste de Tukey, na comparação dos lotes dentro de cada semana (Tabela 9), mostrou uma diferença de comportamento dos lotes na semana 4 em relação às demais e, essa 
discordância, provavelmente, pode ser explicada pelo fato dessa diferença de comportamento ser devida ao valor do lote 3 ter ultrapassado por muito pouco o limite da DMS em relação ao lote 1, na semana 4.

Quando a causa de variação estudada foi semanas, o valor de $\mathrm{F}$ apresentado na Tabela 8 foi significativo ao nível de $1 \%$, indicando que os valores de CT\%Q diferenciaram-se entre as semanas. Para verificar se esse comportamento durante as semanas ajusta-se a alguma função polinomial, foi feito o desdobramento dos GL de semanas e cujos resultados encontramse na Tabela 10.

Tabela 10. Desdobramentos para regressões nas semanas, para CT\%Q Minas Frescal.

\begin{tabular}{lcccc}
\hline \multicolumn{1}{c}{ C. Variações } & G.L. & S.Q. & Q.M. & F \\
\hline Regressão Linear & 1 & 17,14528 & 17,14528 & $1254,96^{* * *}$ \\
Regressão Quadrática & 1 & 0,00813 & 0,00813 & 0,59 \\
Regressão Cúbica & 1 & 0,00449 & 0,00449 & 0,33 \\
Regressão 4º grau & 1 & 0,12857 & 0,12857 & $9,41^{* * *}$ \\
\hline (Semanas) & $(4)$ & $(17,28648)$ & & \\
\hline Resíduo & 24 & 0,32788 & 0,013662 & \\
\hline
\end{tabular}

- Significativo ao nível de $1 \%$.

Pelos resultados obtidos verifica-se um ajuste muito bom para uma função linear, conforme mostra o seu alto valor do teste F. Há, também, um ajuste significativo para uma função polinomial até o $4^{0}$ grau. 


\subsubsection{Extrato seco}

$\mathrm{Na}$ Tabela 11 são apresentados os resultados da análise de variância para os valores de extrato seco \% queijo Minas Frescal obtidos neste trabalho.

Tabela 11. Análise de variância para extrato seco \% queijo Minas Frescal.

\begin{tabular}{lccrc}
\hline \multicolumn{1}{c}{ C. Variações } & G.L. & S.Q. & Q.M. & F \\
\hline Lotes (L) & 2 & 46,18668 & 23,093341 & $5,67^{* *}$ \\
Resíduo (a) & 6 & 24,44787 & 4,074646 & \\
\hline (Parcelas) & $(8)$ & $(70,63455)$ & & \\
\hline Semanas (S) & 4 & 71,90579 & 17,976449 & $13,85^{* * *}$ \\
Int. L x S & 8 & 40,36070 & 5,045088 & $3,89^{* * *}$ \\
Residuo & 24 & 31,16041 & 1,298351 & \\
\hline Total & 44 & 214,06145 & & \\
*** Significativo ao nível de 5\%. & & & \\
$*$ - Significativo ao nivel de $1 \%$. & & &
\end{tabular}

Pelos resultados apresentados, verificamos que existe pelo menos um contraste significativo ao nível de $5 \%$ entre os comportamento dos 3 lotes durante as quatro semanas. O teste de Tuckey aplicado às médias para o total das semanas de cada lote, cujos resultados aparecem na Tabela 12, mostram que o lote 1 , na média, diferiu dos lotes 2 e 3 que se comportaram de forma significativamente semelhante. 
Tabela 12. Média de extrato seco \% queijo Minas Frescal e teste de Tuckey ${ }^{1}$ ao nível de $5 \%$ de probabilidade.

\begin{tabular}{cccccc|c}
\hline Lote & \multicolumn{5}{c|}{ S e m a n a s } & Média \\
\cline { 2 - 5 } & 0 & 1 & 2 & 3 & 4 & \\
\hline 1 & $46,74^{\mathrm{a}}$ & $46,21^{\mathrm{a}}$ & $48,30^{\mathrm{a}}$ & $50,76^{\mathrm{a}}$ & $49,74^{\mathrm{a}}$ & $48,350^{\mathrm{a}}$ \\
2 & $45,66^{\mathrm{ab}}$ & $45,07^{\mathrm{a}}$ & $47,70^{\mathrm{b}}$ & $47,69^{\mathrm{b}}$ & $49,06^{\mathrm{a}}$ & $47,036^{\mathrm{b}}$ \\
3 & $43,14^{\mathrm{b}}$ & $47,36^{\mathrm{a}}$ & $45,59^{\mathrm{b}}$ & $47,31^{\mathrm{b}}$ & $45,94^{\mathrm{b}}$ & $45,868^{\mathrm{b}}$ \\
\hline DMS & 2,7747 & 2,7747 & 2,7747 & 2,7747 & 2,7747 & 2,262 \\
\hline
\end{tabular}

T. Letras diferentes na mesma coluna, indicam diferença significativa entre os valores.

Observando-se os valores de ES\%Q na Tabela 12, verificou-se uma leve tendência de elevação desses valores com o decorrer das semanas. Esse acrescimo está, muito provavelmente, associado a uma pequena dessoragem, inevitável, e que foi notada visualmente nos queijos durante o período de armazenamento. Como foi observado para outros tipos de queijos, por Dolezalek et al. (1981), e para o Minas Frescal, por Wolfschoom-Pombo et al. (1984), essa dessoragem pode ter influído, mesmo em pequena proporção, para o decréscimo no teor de carboidratos totais do queijo, pois, estes encontram-se dissolvidos no soro.

Quando foram comparados os três lotes para o seu comportamento durante as semanas, verificou-se que houve diferenças significativas entre eles, ao nível de $1 \%$ como mostra o valor de F para lotes $\mathrm{x}$ semanas, na Tabela 11 . Feito o desdobramento para lotes dentro de semanas (Tabela 13) os resultados mostram uma variação significativa ao nível de $1 \%$ entre os três lotes, nas semanas 0,3 e 4 e ao nível de $5 \%$ para a semana 2 enquanto que na semana 1 não foi notada variação significativa entre os lotes. Essas observações repetem-se quando foi aplicado o teste de Tuckey, com exceção da semana 2 que, para este teste, não apresentou 
diferença significativa entre os lotes, embora, os lotes 1 e 3 não difiram entre si praticamente no limite da DMS.

Tabela 13. Desdobramento de lotes dentro de semanas,para ES\%Q Minas Frescal.

\begin{tabular}{lcccc}
\hline \multicolumn{1}{c}{ C. Variações } & G.L. & S.Q. & Q.M. & F \\
\hline Lotes dentro de semana 0 & 2 & 20,438449 & 10,219224 & $5,51^{* * *}$ \\
Lotes dentro de semana 1 & 2 & 7,913399 & 3,956700 & 2,13 \\
Lotes dentro de semana 2 & 2 & 12,144347 & 6,072173 & $3,27^{* *}$ \\
Lotes dentro de semana 3 & 2 & 21,531664 & 10,765832 & $5,81^{* * *}$ \\
Lotes dentro de semana 4 & 2 & 24,519524 & 12,259762 & $6,61^{* * *}$ \\
\hline Resíduo & 22 & & 1,853610 & \\
\hline
\end{tabular}

- Significativo ao nível de $5 \%$.

*** - Significativo ao nível de $1 \%$.

Os teores de extrato seco para os três lotes de queijos Minas Frescal durante o transcorrer das semanas apresentaram diferenças significativas ao nível de $1 \%$, conforme o valor de $\mathrm{F}$ para semanas, na Tabela 11, e para verificar se essa variação se ajusta à uma função polinomial, foi feita a análise para regressões nas semanas e os resultados são apresentados na Tabela 14.

Observa-se, pelos resultados da Tabela 14, que houve um ajuste significativo ao nível de $1 \%$, para uma função linear. 
Tabela 14. Desdobramento para regressões nas semanas, para ES\%Q Minas Frescal.

\begin{tabular}{lcccc}
\hline \multicolumn{1}{c}{ C. Variações } & G.L. & S.Q. & Q.M. & F \\
\hline Regressão Linear & 1 & 64,99950 & 64,99950 & $50,06^{* * *}$ \\
Regressão Quadrática & 1 & 3,52364 & 3,52364 & 2,71 \\
Regressão Cúbica & 1 & 2,51870 & 2,51870 & 1,94 \\
Regressão $4^{\circ}$ grau & 1 & 0,86395 & 0,86395 & 0,66 \\
\hline (Semanas) & $(4)$ & $(71,90579)$ & & \\
\hline Resíduo & 24 & 31,16041 & 1,298351 & \\
\hline
\end{tabular}

\footnotetext{
- Significativo ao nível de $1 \%$.
}

\subsubsection{Correlações}

Tendo-se em vista que todos os parâmetros estudados para o queijo Minas Frescal apresentaram variações durante o transcorrer das quatro semanas, foi feito um estudo das correlações entre as semanas e as variações de $\mathrm{Ac} \% \mathrm{Q}, \mathrm{CT} \% \mathrm{Q}$ e ES\%Q. Também, devido ao fato da acidez aumentar à medida que os carboidratos vão sendo consumidos pelas bactérias ácido-laticas e transformados em produtos ácidos, foi verificada a correlação entre $\mathrm{CT} \% \mathrm{Q}$ e $\mathrm{Ac} \% \mathrm{Q}$. Os resultados para essas correlações encontram-se na Tabela 15.

Pelos resultados observados, todas as correlações estudadas foram significativas. Esses resultados são semelhantes àqueles encontrados por Wolfschoom-Pombo et al. (1984) quando estudaram o queijo Minas Frescal até 14 dias após sua fabricação e encontraram coeficientes de correlação de 
Tabela 15. Correlações para parâmetros estudados para o queijo Minas Padrão.

\begin{tabular}{llll}
\hline \multicolumn{1}{c}{ Parâmetro } & $\mathrm{Ac} \% \mathrm{Q}$ & $\mathrm{CT} \% \mathrm{Q}$ & $\mathrm{ES} \% \mathrm{Q}$ \\
\hline Semana & $0,697^{* * *}$ & $-0,936^{* * *}$ & $-0,580^{* *}$ \\
$\mathrm{CT} \% \mathrm{Q}$ & $-0,794^{* * *}$ & & \\
\hline
\end{tabular}

- Significativo ao nível de $10 \%$.

** - Significativo ao nível de $5 \%$.

*** - Significativo ao nível de $1 \%$.

0,$79 ;-0,90$ e 0,68 , respectivamente, entre tempo e $\mathrm{Ac} \% \mathrm{Q}, \mathrm{CT} \% \mathrm{Q}$ e $\mathrm{ES} \% \mathrm{Q}$, e, $-0,89$ entre $C T \% Q$ e $A c \% Q$.

\subsection{Queijo Minas Padrão}

Os valores médios para cada um dos três lotes, no transcorrer das quatro semanas, para acidez titulável, carboidratos totais e extrato seco \% queijo, encontram-se nas Tabelas 17, 21 e 25, respectivamente.

Para o queijo Minas Frescal, os resultados das análises de cada queijo, em separado, encontram-se nas Tabelas A4, A5 e A6, do Apêndice.

\subsubsection{Acidez titulável}

Para os valores de acidez titulável nos queijos Minas Padrão, os resultados da análise de variância, apresentados na Tabela 16, mostram não ter havido nenhum contraste significativo até o nível de $10 \%$, entre os 
comportamentos dos três lotes no decorrer das semanas, conforme mostra o valor de F, não significativo para lotes.

Tabela 16. Análise de variância para acidez titulável nos queijos Minas Padrão.

\begin{tabular}{lcccc}
\hline \multicolumn{1}{c}{ C. Variações } & G.L. & S.Q. & Q.M. & F \\
\hline Lotes (L) & 2 & 0,02997 & 0,14987 & 2,85 \\
Resíduo (a) & 6 & 0,03154 & 0,005256 & \\
\hline (Parcelas) & $(8)$ & $(0,06151)$ & & \\
\hline Semanas (S) & 4 & 0,01776 & 0,004440 & 2,31 \\
Int. L x S & 8 & 0,24153 & 0,030191 & $15,73^{* * *}$ \\
Resíduo & 24 & 0,04606 & 0,001919 & \\
\hline Total & 44 & 0,36686 & & \\
\hline T:* & &
\end{tabular}

- Significativo ao nível de $1 \%$

Esse fato foi confirmado pelo teste de Tuckey quando aplicado às médias para o total das semanas de cada lote e cujos resultados estão na Tabela 17, que contém os valores médios de Ac\%Q para os três queijos de cada lote, nas semanas 0 a 4 , e no total das semanas. Pelos valores das médias e da DMS, não há diferença significativa entre os três lotes.

Pela observação dos resultados na Tabela 17, nota-se que a acidez titulável apresentou valores mais elevados que para o queijo Minas Frescal. Apresentou-se com comportamento irregular, com acréscimos e decréscimos durante o transcorrer das semanas, apresentando valores muito próximos entre o início e o final do experimento. A explicação para esses valores e comportamento, provavelmente, está no fato de os queijos Minas Padrão sofrerem um período de 21 dias de maturação durante o qual, pode 
Tabela 17. Média da acidez titulável ${ }^{1}$ em queijo Minas Padrão e teste de Tuckey $^{2}$ ao nível de $5 \%$ de probabilidade.

\begin{tabular}{cccccc|c}
\hline Lote & \multicolumn{5}{c|}{ S e m a n a s } & \multirow{2}{*}{ Média } \\
\cline { 2 - 5 } & 0 & 1 & 2 & 3 & 4 & \\
\hline 1 & $0,467^{\mathrm{a}}$ & $0,387^{\mathrm{a}}$ & $0,294^{\mathrm{a}}$ & $0,426^{\mathrm{a}}$ & $0,312^{\mathrm{a}}$ & $0,377^{\mathrm{a}}$ \\
2 & $0,402^{\mathrm{a}}$ & $0,390^{\mathrm{a}}$ & $0,384^{\mathrm{ab}}$ & $0,486^{\mathrm{b}}$ & $0,444^{\mathrm{b}}$ & $0,421^{\mathrm{a}}$ \\
3 & $0,366^{\mathrm{a}}$ & $0,516^{\mathrm{b}}$ & $0,486^{\mathrm{b}}$ & $0,267^{\mathrm{c}}$ & $0,558^{\mathrm{c}}$ & $0,439^{\mathrm{a}}$ \\
\hline DMS & 0,1036 & 0,1036 & 0,1036 & 0,1036 & 0,1036 & 0,081 \\
\hline
\end{tabular}

- Expressa em gramas de ácido lático/100g de queijo.

${ }^{2}$ - Letras diferentes na mesma coluna, indicam diferença significativa entre os valores.

ocorrer o mesmo mecanismo relatado por Wolfschoom-Pombo (1984) para o queijo Minas Frescal, com as bactérias láticas originalmente presentes e as inoculadas, procedendo à transformação da lactose com formação de ácido lático que, a seguir, vai sendo neutralizado a lactato de cálcio. Acrescente-se, ainda, que os queijos Minas Padrão utilizados neste trabalho foram adquiridos já com 20 a 23 dias de fabricação, o que aumenta a probabilidade de acidez mais elevada.

Embora, na média, os lotes não tenham apresentado diferenças significativas entre si, o comportamento dos lotes dentro de semanas apresentou pelo menos um contraste significativo ao nível de $1 \%$, verificado pelo valor de $F$, na Tabela 16. Para verificar o comportamento dos lotes dentro de cada semana, foi feito o desdobramento apresentado na Tabela 18 e que apresenta comportamentos diferentes para os lotes, ao nível de $5 \%$ na semana 0 e a $1 \%$ nas demais.

Pelo teste de Tuckey, na comparação dos lotes dentro de cada semana (Tabela 17), verificou-se que essa diferença de comportamento realmente ocorreu de forma significativa para as semanas 1 a 4 enquanto 
Tabela 18. Desdobramento de lotes dentro de semanas, para Ac\%Q Minas Padrão.

\begin{tabular}{lcccc}
\hline \multicolumn{1}{c}{ C. Variações } & G.L. & S.Q. & Q.M. & F \\
\hline Lotes dentro de semana 0 & 2 & 0,015833 & 0,007916 & $3,06^{* *}$ \\
Lotes dentro de semana 1 & 2 & 0,032526 & 0,016263 & $6,29^{* * *}$ \\
Lotes dentro de semana 2 & 2 & 0,055368 & 0,027684 & $10,70^{* * *}$ \\
Lotes dentro de semana 3 & 2 & 0,076842 & 0,038421 & $14,86^{* * *}$ \\
Lotes dentro de semana 4 & 2 & 0,090936 & 0,045468 & $17,58^{* * *}$ \\
\hline Resíduo & 24 & & 0,002586 & \\
\hline
\end{tabular}

- Significativo ao nível de $5 \%$.

$* * * *$ - Significativo ao nível de $1 \%$.

que para a semana 0 , embora o teste de Tuckey não tenha mostrado diferença significativa entre o lote 1 e 3 esses valores estão no limite extremo de DMS, o que pode ter possibilitado o $\mathrm{F}$ significativo ao nível de $5 \%$ na análise de variância.

Quando a comparação foi feita para semanas, o valor de $F$, na Tabela 16, não foi significativo, o que indica que a acidez demonstrou um comportamento médio semelhante no decorrer das semanas para os três lotes estudados.

Para verificar que função polinomial ajusta-se melhor aos resultados da acidez no decorrer das semanas, foi feito o desdobramento apresentado na Tabela 19.

Observa-se, pelos resultados apresentados na Tabela 19 que há um ajuste significativo de uma função polinomial até o $3^{\circ}$ grau. 
Tabela 19. Desdobramento para regressões nas semanas, para Ac\%Q Minas Padrão.

\begin{tabular}{lcccc}
\hline \multicolumn{1}{c}{ C. Variações } & G.L. & S.Q. & Q.M. & F \\
\hline Regressão Linear & 1 & 0,00019 & 0,00019 & 0,10 \\
Regressão Quadrática & 1 & 0,00637 & 0,00637 & $3,32^{* *}$ \\
Regressão Cúbica & 1 & 0,00940 & 0,00940 & $4,90^{* * *}$ \\
Regressão 4º grau & 1 & 0,00180 & 0,00180 & 0,94 \\
\hline (Semanas) & $(4)$ & $(0,01776)$ & & \\
\hline Resíduo & 24 & 0,04606 & 0,001919 & \\
\hline
\end{tabular}

*** - Significativo ao nível de $5 \%$.

${ }^{* * *}$ - Significativo ao nível de $1 \%$.

\subsubsection{Carboidratos Totais}

A análise de variância aplicada aos valores de CT\%Q Minas Padrão, apresentou os resultados que se encontram na Tabela 20 . O valor de F significativo ao nível de $5 \%$ para lotes, indica que houve diferença significativa a esse nível, entre os comportamentos dos três lotes.

Nas médias de cada lote para o total das semanas, o teste de Tuckey, cujos resultados encontram-se na Tabela 21, comprova essa diferença mostrando que o lote 2 diferiu dos lotes 1 e 3 .

Os resultados para carboidratos totais \% queijo, apresentados na Tabela 21, revelam uma leve tendência de redução durante o transcorrer das semanas, partindo de um valor inicial bastante baixo, entre 0,113 a $0,183 \%$, inferiores aos relatados por outros autores e que foram 1,8\% (Sá, 1990), 2\% (Faculdade de Saúde Pública da USP, 1971) e 0,5 a 0,6\% (Valle, 1983). Esse baixo teor e, consequentemente, baixo consumo de carboidratos totais 
Tabela 20. Análise de variância para carboidratos totais \% queijo Minas Padrão.

\begin{tabular}{lcccc}
\hline \multicolumn{1}{c}{ C. Variações } & G.L. & S.Q. & Q.M. & F \\
\hline Lotes (L) & 2 & 0,00548 & 0,002741 & $8,28^{* *}$ \\
Resíduo (a) & 6 & 0,00199 & 0,000331 & \\
\hline (Parcelas) & $(8)$ & $(0,00747)$ & & \\
\hline Semanas (S) & 4 & 0,01431 & 0,003579 & $25,80^{* * *}$ \\
Int. L x S & 8 & 0,00697 & 0,000872 & $6,29^{* * *}$ \\
Resíduo & 24 & 0,00333 & 0,000139 & \\
\hline Total & 44 & 0,03208 & & \\
\hline
\end{tabular}

- Significativo ao nível de $5 \%$.

- Significativo ao nível de $1 \%$.

Tabela 21. Média de carboidratos totais ${ }^{1} \%$ queijo Minas Padrão e teste de Tuckey ${ }^{2}$ ao nivel de $5 \%$ de probabilidade.

\begin{tabular}{cccccc|c}
\hline Lote & \multicolumn{5}{c|}{ S e m a n a s } & \multirow{2}{*}{ Média } \\
\cline { 2 - 5 } & 0 & 1 & 2 & 3 & 4 & \\
\hline 1 & $0,113^{\mathrm{a}}$ & $0,128^{\mathrm{a}}$ & $0,130^{\mathrm{a}}$ & $0,106^{\mathrm{a}}$ & $0,101^{\mathrm{a}}$ & $0,116^{\mathrm{a}}$ \\
2 & $0,183^{\mathrm{b}}$ & $0,165^{\mathrm{b}}$ & $0,129^{\mathrm{a}}$ & $0,100^{\mathrm{a}}$ & $0,121^{\mathrm{ab}}$ & $0,140^{\mathrm{b}}$ \\
3 & $0,148^{\mathrm{c}}$ & $0,121^{\mathrm{a}}$ & $0,123^{\mathrm{a}}$ & $0,105^{\mathrm{a}}$ & $0,090^{\mathrm{a}}$ & $0,117^{\mathrm{a}}$ \\
\hline DMS & 0,0271 & 0,0271 & 0,0271 & 0,0271 & 0,0271 & 0,020 \\
\hline
\end{tabular}

- Expressa em gramas de ácido lático/100g de queijo.

$2^{2}$ - Letras diferentes na mesma coluna, indicam diferença significativa entre os valores.

durante as quatro semanas, explica as pequenas variações ocorridas na acidez titulável, ao contrário do que ocorreu no queijo Minas Frescal.

$\mathrm{O}$ valor de $\mathrm{F}$ para a interação lotes x semanas (Tabela 20), significativo ao nível de $1 \%$, indica que houve diferença entre comportamentos de lotes em semanas diferentes. Para se visualizar melhor esse comportamento, fez-se o desdobramento apresentado na Tabela 22 e 
que demonstra comportamentos diferentes, ao nível de $1 \%$, para as semanas 0,1 e 4 .

Tabela 22. Desdobramento de lotes dentro de semanas para CT\%Q Minas Padrão.

\begin{tabular}{lcccc}
\hline C. Variações & G.L. & S.Q. & Q.M. & F \\
\hline Lotes dentro de semana 0 & 2 & 0,007442 & 0,003721 & $21,02^{* * *}$ \\
Lotes dentro de semana 1 & 2 & 0,003398 & 0,001699 & $9,60^{* * *}$ \\
Lotes dentro de semana 2 & 2 & 0,000082 & 0,000041 & 0,23 \\
Lotes dentro de semana 3 & 2 & 0,000048 & 0,000024 & 0,14 \\
Lotes dentro de semana 4 & 2 & 0,001486 & 0,000743 & $4,20^{* * *}$ \\
\hline Resíduo & 27 & & 0,000177 & \\
\hline
\end{tabular}

*** - Significativo ao nível de $1 \%$.

Pelo teste de Tuckey (Tabela 21), comprova-se esse comportamento com o lote 2 diferindo significativamente do 1 e 3 para essas semanas.

Quando a comparação foi para as semanas, houve diferença significativa ao nível de $1 \%$ conforme mostra o resultado do teste $\mathrm{F}$ na Tabela 20. Para se verificar se esse comportamento, na média, segue uma tendência polinomial, foi feito o desdobramento apresentado na Tabela 23.

Conclui-se pelos resultados da Tabela 23 que houve um ajuste significativo de uma função polinomial até o $3^{\mathrm{o}}$ grau mas, a linear ajusta-se muito bem como mostra seu valor de F bem superior aos demais. 
Tabela 23. Desdobramento para regressões nas semanas, para CT\%Q Minas Padrão.

\begin{tabular}{lcccc}
\hline \multicolumn{1}{c}{ C. Variações } & G.L. & S.Q. & Q.M. & F \\
\hline Regressão Linear & 1 & 0,01340 & 0,01340 & $96,40^{* * *}$ \\
Regressão Quadrática & 1 & 0,00003 & 0,00003 & 0,22 \\
Regressão Cúbica & 1 & 0,00054 & 0,00054 & $3,88^{* *}$ \\
Regressão 4º grau & 1 & 0,00033 & 0,00033 & 2,37 \\
\hline (Semanas) & $(4)$ & $(0,01431)$ & & \\
\hline Resíduo & 24 & 0,00333 & 0,000139 & \\
\hline
\end{tabular}

- Significativo ao nível de $5 \%$.

*** - Significativo ao nível de $1 \%$.

\subsubsection{Extrato seco}

$\mathrm{Na}$ Tabela 24 estão apresentados os resultados da análise de variância para os valores de extrato seco \% queijo Minas Padrão obtidos.

Tabela 24. Análise de variância para extrato seco \% queijo Minas Padrão.

\begin{tabular}{lcccc}
\hline \multicolumn{1}{c}{ C. Variações } & G.L. & S.Q. & Q.M. & F \\
\hline Lotes (L) & 2 & 42,82611 & 21,413054 & $16,93^{* * *}$ \\
Resíduo (a) & 6 & 7,59067 & 1,265112 & \\
\hline (Parcelas) & $(8)$ & $(50,41678)$ & & \\
\hline Semanas (S) & 4 & 34,99260 & 8,748149 & $12,07^{* * *}$ \\
Int. L x S & 8 & 73,59399 & 9,199249 & $12,69^{* * *}$ \\
Resíduo & 24 & 17,39696 & 0,724873 & \\
\hline Total & 44 & 176,40033 & & \\
\hline
\end{tabular}

- Significativo ao nível de $1 \%$. 
Pelo valor de F para lotes, verifica-se que houve pelo menos um contraste significativo ao nível de $1 \%$ entre os comportamentos dos três lotes durante as quatro semanas. O teste de Tuckey aplicado às médias para o total das semanas de cada lote, cujos resultados estão na Tabela 25, mostram que, na média, o lote 1 diferiu significativamente dos lotes 2 e 3 .

Tabela 25. Média de extrato seco \% queijo Minas Padrão e teste de Tuckey ${ }^{1}$ ao nível de $5 \%$ de probabilidade.

\begin{tabular}{cccccc|c}
\hline Lote & \multicolumn{5}{c|}{ S e m a n a s } & Média \\
\cline { 2 - 5 } & 0 & 1 & 2 & 3 & 4 & \\
\hline 1 & $57,169^{\mathrm{a}}$ & $57,838^{\mathrm{a}}$ & $57,157^{\mathrm{a}}$ & $58,663^{\mathrm{a}}$ & $59,251^{\mathrm{a}}$ & $58,018^{\mathrm{a}}$ \\
2 & $58,554^{\mathrm{ab}}$ & $57,647^{\mathrm{a}}$ & $57,075^{\mathrm{a}}$ & $61,000^{\mathrm{b}}$ & $62,847^{\mathrm{b}}$ & $59,425^{\mathrm{b}}$ \\
3 & $59,906^{\mathrm{b}}$ & $59,908^{\mathrm{b}}$ & $62,532^{\mathrm{b}}$ & $58,755^{\mathrm{a}}$ & $60,557^{\mathrm{a}}$ & $60,392^{\mathrm{b}}$ \\
\hline DMS & 1,8600 & 1,8600 & 1,8600 & 1,8600 & 1,8600 & 1,260 \\
\hline
\end{tabular}

- Letras diferentes na mesma coluna, indicam diferença significativa entre os valores.

Os valores de extrato seco apresentados na Tabela 25, para o queijo Minas Padrão, estão em concordância com aqueles encontrados em alguns trabalhos como Valle (1983) que apresenta valores entre 58 e $60 \%$ e Furtado \& Lourenço Neto (1974) com 58,13 a 60,22\%.

$\mathrm{O}$ valor de $\mathrm{F}$ para a interação lotes $\mathrm{x}$ semanas apresentou significância ao nível de $1 \%$, indicando que houve uma diferença significativa para os comportamentos dos lotes nas semanas. Para verificar o comportamento dos lotes dentro de cada semana fez-se o desdobramento apresentado na Tabela 26 que mostra valores de F significativos ao nível de $1 \%$ para todas as semanas, ou seja, houve variação significativa no comportamento dos lotes em todas as semanas. 
Tabela 26. Desdobramento para lotes dentro de semanas, para ES\%Q Minas Padrão.

\begin{tabular}{lcccc}
\hline \multicolumn{1}{c}{ C. Variações } & G.L. & S.Q. & Q.M. & F \\
\hline Lotes dentro de semana 0 & 2 & 11,231568 & 5,615784 & $6,74^{* * *}$ \\
Lotes dentro de semana 1 & 2 & 9,430931 & 4,715466 & $5,66^{* * *}$ \\
Lotes dentro de semana 2 & 2 & 65,352026 & 32,676013 & $39,23^{* * *}$ \\
Lotes dentro de semana 3 & 2 & 10,516316 & 5,258158 & $6,31^{* * *}$ \\
Lotes dentro de semana 4 & 2 & 19,889256 & 9,944628 & $11,94^{* * *}$ \\
\hline Resíduo & 28 & & 0,832921 & \\
\hline
\end{tabular}

- Significativo ao nível de $1 \%$.

O teste de Tuckey, cujos resultados encontram-se na Tabela 25, comprova essa diferença de comportamento dos lotes dentro das semanas 0 a 4 .

Quando a causa de variação estudada foi semanas, o valor de $\mathrm{F}$ foi significativo ao nível de $1 \%$ (Tabela 24 ) indicando que os valores de CT\%Q diferenciaram-se entre as semanas e, assim, foi feito 0 desdobramento apresentado na Tabela 27.

Tabela 27. Desdobramento para regressões nas semanas, para ES\%Q Minas Padrão.

\begin{tabular}{|c|c|c|c|c|}
\hline C. Variações & G.L. & S.Q. & Q.M. & $\bar{F}$ \\
\hline Regressão Linear & 1 & 29,15624 & 29,15624 & $40,22^{* * *}$ \\
\hline Regressão Quadrática & 1 & 5,32183 & 5,32183 & $7,34^{* * *}$ \\
\hline Regressão Cúbica & 1 & 0,09511 & 0,09511 & 0,13 \\
\hline Regressão $4^{\circ}$ grau & 1 & 0,41940 & 0,41940 & 0,58 \\
\hline (Semanas) & (4) & $(34,99260)$ & & \\
\hline Resíduo & 24 & 17,39696 & 0,724873 & \\
\hline
\end{tabular}

- Significativo ao nivel de $1 \%$. 
Verifica-se, pelos resultados da Tabela 27, que houve um ajuste significativo de uma função quadrática para o comportamento médio dos lotes no transcorrer das semanas.

\subsubsection{Correlações}

Da mesma forma que para o queijo Minas Frescal, também para o Minas Padrão foi feito um estudo das correlações entre as semanas e as variações de $A c \% Q, C T \% Q$ e $E S \% Q$ e entre $C T \% Q$ e $A C \% Q$. Os resultados são apresentados na Tabela 28.

Tabela 28. Correlações para parâmetros estudados para o queijo Minas Padrão.

\begin{tabular}{llll}
\hline Parâmetro & Ac\%Q & CT\%Q & ES\%Q \\
\hline Semana & 0,220 & $-0,668^{* * *}$ & 0,445 \\
CT\%Q & $-0,131$ & & \\
\hline & & \\
${ }^{* *}$ - Significativo ao nível de $10 \%$. & \\
${ }^{* * *}$ - Significativo ao nível de $5 \%$. & \\
&
\end{tabular}

Pelos resultados obtidos, verifica-se que para o queijo Minas Padrão, apenas a correlação semanas x CT\%Q apresentou correlação significativa, bem menor que aquela apresentada pelo queijo Minas Frescal. 


\section{CONCLUSÕES}

Pela análise dos dados obtidos e para as condições em que foi desenvovido este trabalho, pode-se chegar às seguintes conclusões:

5.1 A metodologia descrita por Acton (1977) aplica-se à determinação de carboidratos totais em queijos Minas Frescal e Minas Padrão, com maior precisão dos resultados quando a amostra, preparada para a análise, apresenta até $40 \mu \mathrm{g}$ lactose $/ \mathrm{ml}$.

5.2 O queijo Minas Frescal, com dois dias de fabricação, apresenta variações significativas, entre lotes distintos, para $\mathrm{Ac} \% \mathrm{Q}$ e $\mathrm{ES} \% \mathrm{Q}$.

5.3 Existe elevada correlação negativa entre a variação do teor de carboidratos e da acidez titulável para o queijo Minas Frescal, durante período de 2 até 30 dias após sua fabricação.

5.4 Para os queijos Minas Frescal e Padrão, existe uma significativa correlação negativa entre tempo e $\mathrm{CT} \% \mathrm{Q}$, mas apenas o Minas Frescal apresenta a correspondente correlação positiva para Ac\%Q. 
5.5 Para os queijos Minas Frescal, as variações de CT\%Q, Ac\%Q e ES\%Q durante o transcorrer das quatro semanas, ajustam-se à funções lineares com elevado grau de significância.

5.6 Os teores de carboidratos totais encontrados para ambos os tipos de queijo estudados, estão em acordo com aqueles citados por outros autores.

5.7 O queijo Minas Padrão, praticamente, não apresenta variações em sua acidez titulável durante um período de 28 dias de armazenagem a $7^{\circ} \mathrm{C}$. 


\section{REFERÊNCIAS BIBLIOGRÁFICAS}

ACTON, G. H. The determination of lactose in cheese. The Australian Journal of Dairy Technology, p. 111, Sep. 1977.

BARNETT, A. J. G.; TAWAB, G. A. A rapid method for the determination of lactose in milk and cheese. Journal Science Food Agriculture, v. 8, p. 437-441, Jul. 1957.

BLAIS, B. W.; VAILHEN, C. A novel enzymatic microassay for the determination of lactose in grated parmesan cheese. Food Control, v. 6, n. 4, p. 215-217, 1995.

BONASSI, I. A. Estudos de alguns aspectos da produção e cura do queijo tipo Minas. Botucatu, 1973. 101p. Tese (Doutorado) - Faculdade de Ciências Médicas e Biológicas, Universidade Estadual Paulista "Júlio de Mesquita Filho".

BOUZAS, J.; KANTT, C. A.; BODYFELT, F. W.; TORRES, J. A. Temperature effects on chemical characteristics during maturation of 
Cheddar cheese. Journal of Dairy Science, v. 74, p. 86, Abstracts 1991. Supplement, 1.

DAVIS, J. G. Cheese. Ist ed. London: J. \& A. Churchill Ltd., 1965. 463 p.

DOLEZALEK, J.; BEZDEKA, Z.; BOHACENKO, I. Lactose fermentation during cheese production and ripening. Sbornik Vysoke Skoly chemicko-technologicke v Praze - Potraviny, v. 51, p. 175-189, 1981.

DUBOIS, M.; GILLES, K. A.; HAMILTON, J. K.; REBERS, P. A.; SMITH, F. Colorimetric method for determination of sugars and related substances. Analytical Chemistry, v. 28, n.3, p. 350-356, Mar. 1956.

FACULDADE DE SAÚDE PÚBLICA DA USP. Tabela de Composição Química dos Alimentos. Departamento de Nutrição, mimiografado, $1971,13 \mathrm{p}$.

FAGEN, H. J.; SIBBACH, E.; HUSSONG, R. V. The use of anthrone for the quantitative estimation of lactose in dairy products. Journal of Dairy Science, v. 37, n. 1, p. 10-13, Jan. 1954.

FARKYE, N. Y.; FOX, P. F. Objective indices of cheese ripening. Trends in Food Science \& Technology, v. 1, n. 2[2], p. 37-40, Aug. 1990. 
FURTADO, M. M. Queijo Minas: breve histórico e atual situação. Boletim do Leite, n. 662, p. 14-22, Dez. 1983.

FURTADO, M. M.; LOURENÇO NETO, J. P. de M. Estudo rápido sobre a composição média dos queijos Prato e Minas no mercado. Boletim do Leite, n. 605, p. 4-38, Mar. 1979.

KARAHADIAN, C.; LINDSAY, R. C. Integrated roles of lactose, ammonia, and calcium in texture development of mold surface-ripened cheese. Journal of Dairy Science, v. 70, n. 5, p. 909-918, 1987.

KOMBILA-MOUNDOUNGA, E.; LACROIX, C. Effet des combinaisons de chlorure de sodium, de lactose et de glycérol sur les caractéristiques rhéologiques et la couleur des fromages fondus à tartiner. Canadian Institute of Food Science and Technology Journal, v. 24, n. 5, p. 239-251, 1991.

LANARA. Métodos analíticos oficiais para controle de produtos de origem animal e seus ingredientes. Métodos físicos e químicos. Secretaria Nacional de Defesa Agropecuária, Ministério da Agricultura, Brasília, 1981.

LAWRENCE, A. J. The determination of lactose in milk products. The Australian Journal of Dairy Technology, v. 23, p. 103, Jun. 1968. 
MARIER; J. R.; BOULET, M. Direct analysis of lactose in milk and serum. Journal of Dairy Science, v. 42, p. 1390-1391, 1959.

NICKERSON, T. A.; VUJICIC, I. F.; LIN, A. Y. Colorimetric estimation of lactose and its hydrolytic products. Journal of Dairy Science, v. 59, n. 3 , p. 386-390, 1976.

POLLMAN, R. M. Detection of adulteration in grated cheese by using calcium, phosphorus, magnesium, and lactose indices. Journal Association Official Analitical Chemistry, v. 67, n. 6, p. 1062-1066, 1984.

RASMUSSEN, S. B. Las enzimas en la industria láctea. La Alimentación Latinoamericana. Buenos Aires, v. 13, n. 110, p. 57-66, set./out., 1979.

SÁ, N. G. de. Nutrição e Dietética. São Paulo: Livraria Nobel S.A., 1990. $174 \mathrm{p}$.

SCOTT, R. Fabricación de queso. Trad. de F. S. Trepat. Zaragoza: Editorial ACRIBIA S.A., 1991. 520p.

THOMAS, T. D.; PEARCE, K. N. Influence of salt on lactose fermentation and proteolysis in Cheddar cheese. New Zealand Journal of Dairy Science and Technology, v. 16, n. 3, p. 253-259, Dec. 1981. 
VALLE, J. L. E. Influência da coagulação nas características do queijo tipo Minas maturado - momento do corte. Piracicaba, 1983. 44p. Dissertação (Mestrado) - Escola Superior de Agricultura "Luiz de Queiroz", Universidade de São Paulo.

WOLFSCHOON-POMBO, A. F; CASAGRANDE, H. de R.; LOURENÇO NETO, J. P. de M.; MUNCK, A. V. Alterações no queijo Minas Frescal durante o período de armazenamento. Revista do Instituto de Laticínios "Cândido Tostes", v. 39, n. 233, p. 3-9, 1984.

WOLFSCHOON-POMBO, A. F.; LOURENÇO NETO, J. P. M.; HAJDENWURCEL, J. R.; COSTA, D. L. S.; SOBRAL, M. L. Queijo Minas padrão: aspectos físico-químicos e microbiológicos nas primeiras 48 horas de fabricação. Revista do Instituto de Laticínios "Cândido Tostes", v. 41, n. 245, p. 30-34, 1986. 
APÊNDICE 
Tabela A1. Acidez titulável ${ }^{*}$ para o queijo Minas Frescal

\begin{tabular}{ccccccc}
\hline \multirow{2}{*}{ Lote } & Queijo & $\mathbf{0}$ & $\mathbf{1}$ & $\mathbf{2}$ & $\mathbf{3}$ & $\mathbf{4}$ \\
\hline 1 & A1 & 0,306 & 0,396 & 0,396 & 0,450 & 0,576 \\
& B1 & 0,378 & 0,396 & 0,450 & 0,486 & 0,684 \\
& C1 & 0,360 & 0,378 & 0,396 & 0,468 & 0,612 \\
\hline 2 & A2 & 0,108 & 0,108 & 0,180 & 0,378 & 0,396 \\
& B2 & 0,108 & 0,126 & 0,180 & 0,288 & 0,360 \\
& C2 & 0,072 & 0,126 & 0,126 & 0,207 & 0,360 \\
\hline 3 & A3 & 0,090 & 0,216 & 0,234 & 0,306 & 0,513 \\
& B3 & 0,090 & 0,162 & 0,288 & 0,306 & 0,432 \\
& C3 & 0,072 & 0,162 & 0,270 & 0,234 & 0,468
\end{tabular}

" - Expressa em gramas de ácido lático/100g de queijo

Tabela A2. Carboidratos Totais ${ }^{*} \%$ Queijo Minas Frescal

\begin{tabular}{ccccccc}
\hline \multirow{2}{*}{ Lote } & Queijo & $\mathbf{0}$ & $\mathbf{1}$ & $\mathbf{2}$ & $\mathbf{3}$ & $\mathbf{4}$ \\
\hline 1 & A1 & 2,472 & 2,023 & 1,310 & 1,044 & 0,678 \\
& B1 & 2,323 & 1,825 & 1,522 & 0,917 & 0,435 \\
& C1 & 2,283 & 2,009 & 1,680 & 0,794 & 0,301 \\
\hline 2 & A2 & 3,083 & 2,380 & 2,182 & 1,419 & 0,950 \\
& B2 & 2,681 & 2,159 & 1,954 & 1,403 & 1,037 \\
& C2 & 2,694 & 2,134 & 2,031 & 1,408 & 1,071 \\
\hline 3 & A3 & 2,479 & 1,867 & 1,767 & 1,208 & 0,802 \\
& B3 & 2,408 & 1,815 & 1,564 & 1,162 & 0,749 \\
& C3 & 2,186 & 1,852 & 1,611 & 1,107 & 0,746 \\
\hline
\end{tabular}


Tabela A3. Extrato Seco \% Queijo Minas Frescal

\begin{tabular}{ccccccc}
\hline & & \multicolumn{5}{c}{ Semanas } \\
\cline { 3 - 7 } Lote & Queijo & $\mathbf{0}$ & $\mathbf{1}$ & $\mathbf{2}$ & $\mathbf{3}$ & $\mathbf{4}$ \\
\hline 1 & A1 & 48,473 & 46,573 & 48,341 & 50,402 & 49,505 \\
& B1 & 46,185 & 46,285 & 48,649 & 51,108 & 47,288 \\
& C1 & 45,551 & 45,485 & 47,912 & 50,773 & 52,415 \\
\hline 2 & A2 & 43,290 & 42,517 & 47,154 & 46,956 & 48,704 \\
& B2 & 45,344 & 45,282 & 46,985 & 48,407 & 48,975 \\
& C2 & 48,354 & 47,403 & 48,956 & 47,691 & 49,488 \\
\hline 3 & A3 & 43,305 & 48,501 & 46,006 & 48,867 & 46,693 \\
& B3 & 43,131 & 46,631 & 45,847 & 46,813 & 45,733 \\
& C3 & 42,989 & 46,692 & 44,921 & 46,243 & 45,407 \\
\hline
\end{tabular}

Tabela A4. Acidez titulável ${ }^{*}$ para o queijo Minas Padrão

\begin{tabular}{ccccccc}
\hline \multirow{2}{*}{ Lote } & Queijo & $\mathbf{0}$ & $\mathbf{1}$ & $\mathbf{2}$ & $\mathbf{3}$ & $\mathbf{4}$ \\
\hline 1 & A1 & 0,522 & 0,396 & 0,324 & 0,432 & 0,306 \\
& B1 & 0,396 & 0,396 & 0,270 & 0,396 & 0,288 \\
& C1 & 0,486 & 0,369 & 0,288 & 0,450 & 0,342 \\
\hline 2 & A2 & 0,486 & 0,405 & 0,378 & 0,558 & 0,486 \\
& B2 & 0,375 & 0,378 & 0,378 & 0,504 & 0,432 \\
& C2 & 0,342 & 0,387 & 0,396 & 0,396 & 0,414 \\
& A3 & 0,414 & 0,522 & 0,486 & 0,306 & 0,612 \\
& B3 & 0,342 & 0,558 & 0,432 & 0,333 & 0,558 \\
& C3 & 0,342 & 0,468 & 0,540 & 0,162 & 0,504
\end{tabular}

\footnotetext{
* - Expressa em gramas de ácido lático/100g de queijo
} 
Tabela A5. Carboidratos Totais * para o Queijo Minas Padrão

\begin{tabular}{ccccccc}
\hline \multirow{2}{*}{ Lote } & Queijo & $\mathbf{0}$ & $\mathbf{1}$ & $\mathbf{2}$ & $\mathbf{3}$ & $\mathbf{4}$ \\
\cline { 3 - 7 } 1 & A1 & 0,1099 & 0,1353 & 0,1542 & 0,1147 & 0,0955 \\
& B1 & 0,1035 & 0,1229 & 0,1142 & 0,1051 & 0,1021 \\
& C1 & 0,1248 & 0,1248 & 0,1226 & 0,0971 & 0,1039 \\
\hline 2 & A2 & 0,1786 & 0,1566 & 0,1187 & 0,1129 & 0,1263 \\
& B2 & 0,1839 & 0,1731 & 0,1494 & 0,0952 & 0,1270 \\
& C2 & 0,1870 & 0,1656 & 0,1186 & 0,0930 & 0,1104 \\
\hline 3 & A3 & 0,1574 & 0,1322 & 0,1311 & 0,1216 & 0,0985 \\
& B3 & 0,1272 & 0,0936 & 0,1115 & 0,0995 & 0,0955 \\
& C3 & 0,1589 & 0,1369 & 0,1274 & 0,0936 & 0,0771 \\
\hline
\end{tabular}

* Expressos como lactose

Tabela A6. Extrato seco \% queijo Minas Padrão

\begin{tabular}{ccccccc}
\hline \multirow{2}{*}{ Lote } & Queijo & $\mathbf{0}$ & $\mathbf{1}$ & $\mathbf{2}$ & $\mathbf{3}$ & $\mathbf{4}$ \\
\hline 1 & A1 & 57,934 & 57,418 & 57,662 & 60,874 & 60,553 \\
& B1 & 56,472 & 57,565 & 57,518 & 57,463 & 59,487 \\
& C1 & 57,103 & 58,532 & 56,290 & 57,650 & 57,712 \\
\hline 2 & A2 & 57,567 & 57,398 & 56,983 & 62,155 & 62,218 \\
& B2 & 59,071 & 57,958 & 57,873 & 60,589 & 62,683 \\
& C2 & 59,025 & 57,586 & 56,368 & 60,258 & 63,641 \\
\hline 3 & A3 & 60,664 & 60,292 & 61,785 & 58,534 & 60,600 \\
& B3 & 59,544 & 59,472 & 62,882 & 58,265 & 59,986 \\
& C3 & 59,509 & 59,959 & 63,827 & 59,466 & 61,085 \\
\hline
\end{tabular}

